\title{
Mindfulness Meditation-Based Pain Relief Employs Different Neural Mechanisms Than Placebo and Sham Mindfulness Meditation-Induced Analgesia
}

\author{
Fadel Zeidan, ${ }^{1}$ Nichole M. Emerson, ${ }^{1}$ Suzan R. Farris, ${ }^{1}$ Jenna N. Ray, ${ }^{3}$ Youngkyoo Jung, ${ }^{2}$ John G. McHaffie, ${ }^{1}$ \\ and Robert C. Coghill ${ }^{4}$ \\ ${ }^{1}$ Department of Neurobiology and Anatomy and ${ }^{2}$ Department of Radiology, Wake Forest School of Medicine, Winston-Salem, North Carolina 27157, \\ ${ }^{3}$ Department of Psychology, University of North Carolina at Charlotte, Charlotte, North Carolina 28262, and ${ }^{4}$ Department of Anesthesiology, Cincinnati \\ Children's Hospital Medical Center, Cincinnati, Ohio 45229
}

Mindfulness meditation reduces pain in experimental and clinical settings. However, it remains unknown whether mindfulness meditation engages pain-relieving mechanisms other than those associated with the placebo effect (e.g., conditioning, psychosocial context, beliefs). To determine whether the analgesic mechanisms of mindfulness meditation are different from placebo, we randomly assigned 75 healthy, human volunteers to $4 \mathrm{~d}$ of the following: (1) mindfulness meditation, (2) placebo conditioning, (3) sham mindfulness meditation, or (4) book-listening control intervention. We assessed intervention efficacy using psychophysical evaluation of experimental pain and functional neuroimaging. Importantly, all cognitive manipulations (i.e., mindfulness meditation, placebo conditioning, sham mindfulness meditation) significantly attenuated pain intensity and unpleasantness ratings when compared to rest and the control condition $(p<0.05)$. Mindfulness meditation reduced pain intensity $(p=0.032)$ and pain unpleasantness $(p<0.001)$ ratings more than placebo analgesia. Mindfulness meditation also reduced pain intensity $(p=0.030)$ and pain unpleasantness $(p=0.043)$ ratings more than sham mindfulness meditation. Mindfulness-meditation-related pain relief was associated with greater activation in brain regions associated with the cognitive modulation of pain, including the orbitofrontal, subgenual anterior cingulate, and anterior insular cortex. In contrast, placebo analgesia was associated with activation of the dorsolateral prefrontal cortex and deactivation of sensory processing regions (secondary somatosensory cortex). Sham mindfulness meditation-induced analgesia was not correlated with significant neural activity, but rather by greater reductions in respiration rate. This study is the first to demonstrate that mindfulness-related pain relief is mechanistically distinct from placebo analgesia. The elucidation of this distinction confirms the existence of multiple, cognitively driven, supraspinal mechanisms for pain modulation.

Key words: arterial spin labeling; fMRI; mindfulness meditation; pain; placebo; psychophysics

Significance Statement

Recent findings have demonstrated that mindfulness meditation significantly reduces pain. Given that the "gold standard" for evaluating the efficacy of behavioral interventions is based on appropriate placebo comparisons, it is imperative that we establish whether there is an effect supporting meditation-related pain relief above and beyond the effects of placebo. Here, we provide novel evidence demonstrating that mindfulness meditation produces greater pain relief and employs distinct neural mechanisms than placebo cream and sham mindfulness meditation. Specifically, mindfulness meditation-induced pain relief activated higherorder brain regions, including the orbitofrontal and cingulate cortices. In contrast, placebo analgesia was associated with decreased pain-related brain activation. These findings demonstrate that mindfulness meditation reduces pain through unique mechanisms and may foster greater acceptance of meditation as an adjunct pain therapy.

\section{Introduction}

The subjective experience of pain is constructed and modulated by complex, multidimensional interactions between sensory, affective, and cognitive factors, making its treatment both challenging and costly. Mindfulness meditation, a cognitive practice based on developing nonjudgmental awareness of arising sensory events, has been shown repeatedly to alleviate pain across experimental and clinical settings (Kabat-Zinn, 1982; Kabat-Zinn et al., 1985; Grant and Rainville, 2009; Brown and Jones, 2010; Zeidan et al., 2010a; Gard et al., 2012; Garland et al., 2012; Grant et al., 2011; Zeidan et al., 2011; MacCoon et al., 2012; Lutz et al., 2013). However, the utilization of mindfulness meditation is lim- 
ited in part because of poor reproducibility of research findings and questions related to mechanistic underpinnings (Tang et al., 2015). For example, mindfulness meditation could simply reduce pain through mechanisms that mediate placebo analgesia, such as conditioning effects (Colloca et al., 2010; Lui et al., 2010). The analgesic effects of meditation could also be driven by the nonspecific components of participating in a meditation intervention. Such components would include psychosocial contexts, facilitator attention, intervention setting, body posture, and/or demand characteristics associated with the belief that one is practicing meditation (Salomons and Kucyi, 2011; Zeidan et al., 2012; Tang et al., 2015).

Despite the commonly held assumption that mindfulness meditation shares much in common with other placebo manipulations, the neural mechanisms supporting mindfulness-based pain relief have yet to be compared with those engaged by placebo analgesia (Salomons and Kucyi, 2011; Zeidan et al., 2012). Accordingly, the present longitudinal study combined psychophysical, physiological, and pseudocontinuous arterial spin-labeled MRI (PCASL) methodologies in pain-free, healthy volunteers to test the hypothesis that mindfulness meditation produces greater pain reductions and activates distinct neural mechanisms from those engaged by placebo analgesia.

To determine whether pain reduction during mindfulness meditation is associated with unique and specific brain mechanisms, we compared the effects of a $4 \mathrm{~d}$ mindfulness meditation intervention to an extension of a well validated, $4 \mathrm{~d}$ placebo conditioning regimen in response to noxious heat stimulation (Price et al., 1999; Colloca et al., 2010; Lui et al., 2010). We predicted that placebo analgesia would be associated with decreased painrelated brain activation and dorsolateral prefrontal cortex (DLPFC) activation, a brain region critically involved in placebo and maintaining contextual expectations for pain relief (Wager et al., 2004; Eippert et al., 2009; Lui et al., 2010; Petrovic et al., 2010; Atlas et al., 2012; Geuter et al., 2013). In contrast, we predicted that mindfulness-based pain relief would be associated with greater activation in sensory processing regions such as the secondary somatosensory cortex (SII) and insula (Grant et al., 2010; Gard et al., 2012; Grant et al., 2011; Zeidan et al., 2011) and higher-order brain regions such as the orbitofrontal cortex (OFC) and anterior cingulate cortex (ACC) (Hölzel et al., 2011; Zeidan et al., 2011; Zeidan et al., 2012).

Given the powerful effects of psychosocial contexts on the subjective experience of pain, it is also important to determine whether the analgesic effects of meditation are simply associated with the nonspecific components (posture, breathing, beliefs, intervention setting) of participating in a meditation intervention. We therefore compared active mindfulness meditation with a validated sham mindfulness meditation technique (Zeidan et al., 2010b). Although the behavioral and neural mechanisms associated with sham mindfulness meditation are not known, it was

Received July 3, 2015; revised Sept. 10, 2015; accepted Sept. 28, 2015.

Author contributions: F.Z., J.G.M., and R.C.C. designed research; F.Z., N.M.E., S.R.F., J.N.R., and Y.J. performed research; F.Z. and R.C.C. analyzed data; F.Z., Y.J., J.G.M., and R.C.C. wrote the paper.

This work was supported by the National Center for Complementary and Integrative Health (Grants R21AT007247, F32-AT006949, K99-AT008238), the National Institutes of Health-National Institute of Neurological Disorders and Stroke (Grant NS239426), a Mind and Life Institute Francisco J. Varela Award, and the Wake Forest Center for Integrative Medicine.

The authors declare no competing financial interests.

Correspondence should be addressed to Fadel Zeidan, Department of Neurobiology and Anatomy, Wake Forest School of Medicine, 1 Medical Center Boulevard, Winston-Salem, NC 27157. E-mail: fzeidan@wakehealth.edu.

DOI:10.1523/JNEUROSCI.2542-15.2015

Copyright $\odot 2015$ the authors $\quad 0270-6474 / 15 / 3515308-19 \$ 15.00 / 0$
Table 1. Participant demographic, FMI, respiration, cerebral blood flow, and heart rate information

\begin{tabular}{lllll}
\hline & Control & Placebo & Mindfulness & Sham \\
\hline Age & $27.84(6.92)$ & $27.42(5.22)$ & $28.06(6.75)$ & $25.95(4.82)$ \\
Sex & $M=10, F=9$ & $M=10, F=9 \mathrm{M}=8, F=9$ & $\mathrm{M}=10, F=10$ \\
FMl preintervention & $40.94(1.38)$ & $41.21(1.97)$ & $37.35(1.21)$ & $42.05(1.46)$ \\
FMl postintervention & $41.73(1.79)$ & $38.79(1.91)$ & $43.06(1.92)^{*}$ & $42.05(1.54)$ \\
RR rest heat & $15.73(0.63)$ & $14.53(0.99)$ & $17.00(0.73)$ & $16.76(0.73)$ \\
RR rest neutral & $15.89(0.57)$ & $15.07(0.79)$ & $16.69(0.81)$ & $16.25(0.67)$ \\
RR manipulation heat & $16.00(0.73)$ & $14.76(0.83)$ & $8.97(1.05)^{* *}$ & $10.63(1.17)^{* *}$ \\
RR manipulation neutral & $15.92(0.56)$ & $14.70(0.63)$ & $9.64(1.03)^{* *}$ & $10.51(0.88)^{* *}$ \\
CBF rest heat & $53.64(2.48)$ & $49.84(1.87)$ & $52.14(2.16)$ & $52.02(1.69)$ \\
CBF rest neutral & $52.74(2.28)$ & $50.97(1.84)$ & $52.28(2.00)$ & $52.88(1.55)$ \\
CBF manipulation heat & $51.17(2.45)$ & $49.14(2.00)$ & $40.29(2.12)^{* * *}$ & $47.08(1.74)^{*}$ \\
CBF manipulation neutral $52.29(2.41)$ & $50.39(2.00)$ & $42.08(2.23)^{* * *} 49.59(1.68)^{*}$ \\
HR rest heat & $71.29(2.88)$ & $71.04(2.46)$ & $63.54(2.54)$ & $69.01(1.52)$ \\
HR rest neutral & $68.64(2.47)$ & $67.43(2.28)$ & $66.98(2.51)$ & $69.72(3.27)$ \\
HR manipulation heat & $69.89(3.19)$ & $68.39(3.05)$ & $65.14(2.17)$ & $67.86(4.06)$ \\
HR manipulation neutral & $68.59(2.70)$ & $66.46(2.26)$ & $64.84(2.18)$ & $66.66(1.50)$ \\
\hline
\end{tabular}

There were no significant differences between groups on age and gender. Group Freiburg Mindfulness Inventory (FMI) ratings (mean \pm SEM) from pre-intervention to post-intervention. Mindfulness meditation significantly increased FMI ratings by $16 \%$ from preintervention to postintervention and when compared to the placebo, shammindfulness meditation and control groups. ${ }^{*} p<0.05$. Mindfulness meditation and sham-mindfulness meditation significantly reduced respiration rate (RR) from rest to their respective manipulations. ${ }^{* *} p<0.001$. There were no significant differences in the change in respiration rate between the genuine mindfulness and sham-mindfulness meditation groups. Mindfulness meditation was associated with significant reductions in cerebral blood flow (CBF) when compared to the rest of the groups. ${ }^{* * *} p<0.002$. Sham-mindfulness meditation also exhibited significant reductions in CBF when compared to rest. There were no between-group differences in heart rate (HR).

hypothesized that sham mindfulness meditation would reduce pain by engaging mechanisms more aligned with placebo analgesia (i.e., DLPFC; Wager and Atlas, 2015) and relaxation (i.e., decreased respiration rate; Beary and Benson, 1974).

\section{Materials and Methods}

\section{Participants}

Eighty healthy, pain-free, right-handed volunteers without any prior meditative experience successfully completed all study sessions. However, MRI-related artifacts compromised data from five subjects. Therefore, data from 75 participants (mean age $=27 \pm 6$ years; 38 males; 37 females) are presented here (Table 1 ). Of the 75 subjects that are included, 56 were white, seven were black, seven were mixed race, and five were Asian. Individuals taking psychotropic or pain medications and pregnant women were excluded. Exclusion criteria also eliminated individuals with prior meditation experience (excluding yoga) and those who practice meditation-based religions/philosophies (i.e., Hinduism, Buddhism, contemplative Christians). Wake Forest School of Medicine's Institutional Review Board approved all study procedures. All subjects provided written, informed consent recognizing the following: (1) that they would experience painful heat stimuli; (2) that all methods were clearly explained; and (3) that they were free to withdraw from the study without prejudice.

\section{Randomization procedure}

After providing written consent, all subjects were randomly assigned to one of four groups and matched on sex with a four-arm block-design randomization procedure. The four treatment arms (A-D) were permuted with respect to treatment assignment (mindfulness meditation, placebo, sham mindfulness meditation, and control). Randomization was stratified by sex so that each sex type would have their respective list of randomization codes.

\section{Stimuli}

As described previously (Koyama et al., 2005; Oshiro et al., 2007; Quevedo and Coghill, 2007a,b, 2009; Starr et al., 2009; Yelle et al., 2009; Zeidan et al., 2011; Lobanov et al., 2013; Lobanov et al., 2014; Zeidan et al., 2015), a TSA-II device (Medoc) was used to deliver all thermal stimuli using a $16 \mathrm{~mm}^{2}$ surface area thermal probe. This modest stimulus area 


\begin{tabular}{|c|c|c|c|c|c|c|c|}
\hline Groups & ES 1 & ES 2 & ES 3 & ES 4 & ES 5 & ES 6 & ES 7 \\
\hline Placebo & $\begin{array}{c}\text { Administer } \\
\text { FMI } \\
\\
\text { PT }\end{array}$ & $\begin{array}{l}\text { Anatomical Scan } \\
\frac{\text { SCAN 1-4: }:{ }^{\circ} \text { EST }}{2\left(\text { heat; } 9{ }^{\circ} \mathrm{C}\right)+} \\
2 \text { (neutral; } 35^{\circ} \mathrm{C} \text { ) }\end{array}$ & \begin{tabular}{|c|}
$\underline{\text { Series } \mathrm{A}\left(49^{\circ} \mathrm{C}\right)}$ \\
Apply/remove cream \\
Series B $\left(48^{\circ} \mathrm{C}\right)$ \\
Assess cream \\
effectiveness ratings
\end{tabular} & $\begin{array}{c}\text { Series } \mathrm{A}\left(49^{\circ} \mathrm{C}\right) \\
\text { Apply/remove cream } \\
\underline{\text { Series B }\left(47^{\circ} \mathrm{C}\right)} \\
\text { Assess cream } \\
\text { effectiveness ratings }\end{array}$ & $\begin{array}{c}\underline{\text { Series A }\left(49^{\circ} \mathrm{C}\right)} \\
\text { Apply/remove cream } \\
\underline{\text { Series B }\left(47^{\circ} \mathrm{C}\right)} \\
\begin{array}{c}\text { Assess cream } \\
\text { effectiveness ratings }\end{array}\end{array}$ & $\begin{array}{c}\text { Series A }\left(49^{\circ} \mathrm{C}\right) \\
\text { Apply/remove cream } \\
\text { Series B }\left(46.5^{\circ} \mathrm{C}\right) \\
\begin{array}{c}\text { Assess cream } \\
\text { effectiveness ratings }\end{array}\end{array}$ & 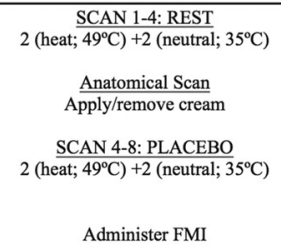 \\
\hline $\begin{array}{l}\text { Mindfulness } \\
\text { Meditation }\end{array}$ & PT & $\begin{array}{l}\text { Anatomical Scan } \\
\text { SCAN 1-4: REST } \\
2 \text { (heat; } ; 9^{\circ} \text { C) }+ \\
2 \text { (neutral; } 35^{\circ} \mathrm{C} \text { ) }\end{array}$ & $\begin{array}{c}\text { Series A }\left(49^{\circ} \mathrm{C}\right) \\
\underline{\text { Series B }\left(48^{\circ} \mathrm{C}\right)} \\
\text { Meditation } \\
\text { Assess meditative } \\
\text { effectiveness ratings }\end{array}$ & $\begin{array}{c}\text { Series } \mathrm{A}\left(49^{\circ} \mathrm{C}\right) \\
\underline{\text { Series B }\left(47^{\circ} \mathrm{C}\right)} \\
\text { Meditation } \\
\begin{array}{c}\text { Assess meditative } \\
\text { effectiveness ratings }\end{array}\end{array}$ & $\begin{array}{c}\text { Series } \mathrm{A}\left(49^{\circ} \mathrm{C}\right) \\
\underline{\text { Series } \mathrm{B}\left(47^{\circ} \mathrm{C}\right)} \\
\text { Meditation } \\
\text { Assess meditative } \\
\text { effectiveness ratings }\end{array}$ & $\begin{array}{c}\text { Series } \mathrm{A}\left(49^{\circ} \mathrm{C}\right) \\
\frac{\text { Series } \mathrm{B}\left(46.5^{\circ} \mathrm{C}\right)}{\text { Meditation }} \\
\text { Assess meditative } \\
\text { effectiveness ratings }\end{array}$ & $\begin{array}{c}\text { SCAN 1-4: REST } \\
\left.2 \text { (heat; } 49^{\circ} \mathrm{C}\right)+2 \text { (neutral; } 35^{\circ} \mathrm{C} \text { ) } \\
\text { Anatomical Scan } \\
\text { "Begin meditating" } \\
2 \text { (hCANat; 49-8: MEDITATION }+2 \text { (neutral; } 35^{\circ} \mathrm{C} \text { ) } \\
\text { Administer FMI }\end{array}$ \\
\hline Sham Meditation & $\begin{array}{c}\text { Administer } \\
\text { FMI } \\
\text { PT }\end{array}$ & $\begin{array}{l}\text { Anatomical Scan } \\
\frac{\text { SCAN 1-4: REST }}{\left.2 \text { (heat; } 49^{\circ} \mathrm{C}\right)+} \\
2 \text { (neutral; } 35^{\circ} \mathrm{C} \text { ) }\end{array}$ & $\begin{array}{c}\text { Series A }\left(49^{\circ} \mathrm{C}\right) \\
\text { Series B }\left(48^{\circ} \mathrm{C}\right) \\
\text { Sham Meditation } \\
\text { Assess meditative } \\
\text { effectiveness ratings }\end{array}$ & $\begin{array}{c}\text { Series A }\left(49^{\circ} \mathrm{C}\right) \\
\text { Series B }\left(47^{\circ} \mathrm{C}\right) \\
\text { Sham Meditation } \\
\text { Assess meditative } \\
\text { effectiveness ratings }\end{array}$ & $\begin{array}{c}\text { Series A }\left(49^{\circ} \mathrm{C}\right) \\
\text { Series B }\left(47^{\circ} \mathrm{C}\right) \\
\text { Sham Meditation } \\
\text { Assess meditative } \\
\text { effectiveness ratings }\end{array}$ & $\begin{array}{c}\text { Series A }\left(49^{\circ} \mathrm{C}\right) \\
\text { Series B }\left(46.5^{\circ} \mathrm{C}\right) \\
\text { Sham Meditation } \\
\text { Assess meditative } \\
\text { effectiveness ratings }\end{array}$ & $\begin{array}{c}\text { SCAN 1-4: REST } \\
\left.2 \text { (heat; } 49^{\circ} \mathrm{C}\right)+2 \text { (neutral; } 35^{\circ} \mathrm{C} \text { ) } \\
\text { “Anatomical Scan } \\
\text { "Begin meditating" } \\
\frac{\text { SCAN 4-8: SHAM MEDITATION }}{\left.2 \text { (heat; } 49^{\circ} \mathrm{C}\right)+2 \text { (neutral; } 35^{\circ} \mathrm{C} \text { ) }} \\
\text { Administer FMI }\end{array}$ \\
\hline Control & $\begin{array}{c}\text { Administer } \\
\text { FMI } \\
\text { PT }\end{array}$ & $\begin{array}{l}\text { Anatomical Scan } \\
\frac{\text { SCAN 1-4: REST }}{2 \text { (heat; } ; 9^{\circ} \text { C) }+} \\
2 \text { (neutral; } 35^{\circ} \mathrm{C} \text { ) }\end{array}$ & $\begin{array}{l}\text { Series } \mathrm{A}\left(49^{\circ} \mathrm{C}\right) \\
\underline{\text { Series B }\left(48^{\circ} \mathrm{C}\right)} \\
\text { Book Listening } \\
\text { Assess listening } \\
\text { effectiveness ratings }\end{array}$ & $\begin{array}{c}\text { Series A }\left(49^{\circ} \mathrm{C}\right) \\
\text { Series B }\left(47^{\circ} \mathrm{C}\right) \\
\text { Book Listening } \\
\text { Assess listening } \\
\text { effectiveness ratings }\end{array}$ & $\begin{array}{l}\text { Series A }\left(49^{\circ} \mathrm{C}\right) \\
\text { Series B }\left(47^{\circ} \mathrm{C}\right) \\
\text { Book Listening } \\
\text { Assess listening } \\
\text { effectiveness ratings }\end{array}$ & $\begin{array}{c}\underline{\text { Series } \mathrm{A}\left(49^{\circ} \mathrm{C}\right)} \\
\underline{\text { Series B }\left(46.5^{\circ} \mathrm{C}\right)} \\
\text { Book Listening } \\
\begin{array}{c}\text { Assess listening } \\
\text { effectiveness ratings }\end{array}\end{array}$ & $\begin{array}{l}2 \text { (heat; } 49^{\circ} \mathrm{C} \text { ) }+2 \text { (nEutral; } 35^{\circ} \mathrm{C} \text { ) } \\
\text { Anatomical Scan } \\
\text { "Keep eyes closed" } \\
\text { 2(heat; } 49^{\circ} \mathrm{C} \text { ) }+2 \text { - } 2 \text { (nEST } \\
\text { Admitral; } 35^{\circ} \mathrm{C} \text { ) } \\
\text { Adminster FMI }\end{array}$ \\
\hline
\end{tabular}

Figure 1. Study procedures across experimental sessions (ES) and groups. ES 1: After completing the FMI, psychophysical training (PT) was conducted. ES 2: After the anatomical scan, two "heat" $\left(49^{\circ} \mathrm{C}\right.$ ) and two "neutral" $\left(35^{\circ} \mathrm{C}\right)$ PCASL series were conducted. ES 3-6: Placebo group: noxious "heat" stimuli were first delivered to untreated skin (Series A). After administering/removing the placebo cream, we delivered another "heat" series to the treated skin region, but covertly and progressively reduced the temperature in Series B (i.e., ES-3 $=48^{\circ} \mathrm{C}$; ES-4 and $5=47^{\circ} \mathrm{C} ; \mathrm{ES}-6=$ $\left.46.5^{\circ} \mathrm{C}\right)$. Mindfulness meditation group: subjects were taught mindfulness meditation skills. Sham mindfulness meditation group: subjects were instructed to "take a deep breath as we sit here in meditation." Control group: subjects listened to an audiobook. We assessed perceived intervention effectiveness after each intervention session. ES 7: We first administered two "heat" and two "neutral" PCASL series. Before acquiring the anatomical MRI, we applied/removed the placebo cream to the placebo group, the mindfulness and sham mindfulness meditation groups were instructed to "begin meditating", and the control group was instructed to keep their eyes closed. We then administered two "heat" and two "neutral" series. The FMI was administered after MRI Session B.

allows a relatively wide range of noxious stimuli to be delivered. The thermal probe was moved to a new stimulation site after each experimental series to reduce habituation. All stimulus temperatures were $\leq 49^{\circ} \mathrm{C}$. Subjects were free to escape the stimulator at any time by lifting their limb. As designed, no stimulus produced tissue damage in this experiment.

\section{Psychophysical assessment of pain}

As previously employed (Coghill and Eisenach, 2003; Coghill et al., 2003; Zeidan et al., 2011), pain intensity and unpleasantness ratings were assessed with a $15 \mathrm{~cm}$ plastic sliding visual analog scale (VAS) (Price et al., 1994). We instructed subjects "that the distinction between the two aspects of pain might be made clearer if you think of listening to a sound, such as a radio. The intensity of pain is like loudness; the unpleasantness of pain depends not only on intensity, but also on other factors which may affect you" (Price et al., 1983). The minimum rating ("0") was designated as "no pain sensation" and "not at all unpleasant," whereas the maximum ("10") was labeled as "most intense pain sensation imaginable" or "most unpleasant sensation imaginable," respectively. These scales have been demonstrated to provide reliably separate assessment of pain intensity and unpleasantness, to be internally consistent, and to approximate ratio scale measurement accuracy (Price, 2000).

\section{Psychological outcomes}

The Freiburg Mindfulness Inventory short form (FMI) is a 14-item assessment designed to assess changes in mindfulness attributed to meditation training. As previously employed (Zeidan et al., 2010a,b,c; Zeidan et al., 2011), the FMI was administered to measure levels of mindfulness before psychophysical pain training and after the last MRI session (Fig. 1). The FMI is a psychometrically valid instrument with high internal consistency (Cronbach $\alpha=0.86$ ) (Walach et al., 2006). Higher scores indicate more skill with the mindfulness technique. As a manipulation check, it was hypothesized that the mindfulness meditation group would significantly increase FMI scores from pre-meditation to postmeditation training.

Perceived intervention effectiveness was assessed with a VAS (" 0 " = not effective at all; "10" = most effective imaginable) for each intervention session's respective manipulation (Zeidan et al., 2010b) and MRI Session B (Fig. 1). After each intervention session and MRI Session B, participants in the mindfulness meditation and sham mindfulness meditation groups were asked, "How effectively did you meditate in this session?" As a manipulation check of our sham mindfulness meditation intervention, it was hypothesized that there would be no differences between the mindfulness and sham mindfulness meditation groups on "perceived meditative effectiveness." After each placebo conditioning 
session, subjects in the placebo group were asked, "How effective was the 'lidocaine' cream at reducing pain?" After each book-listening control session, control subjects were asked, "How effectively did you listen to the audiobook?"

\section{Anatomical MRI acquisition}

Participants were scanned on a 3T Siemens Skyra scanner with a 32channel head coil. High-resolution T1-weighted images were obtained using a MP-RAGE sequence: flip angle $=9^{\circ}, \mathrm{TI}=900 \mathrm{~ms}$, $\mathrm{TE}=2.95$, $\mathrm{TR}=2300 \mathrm{~ms}$, pixel bandwidth $=240 \mathrm{~Hz} /$ pix, $\mathrm{FOV}=25.6 \times 24 \mathrm{~cm}, 192$ number of slices, $1 \mathrm{~mm}$ isotropic spatial resolution, GRAPPA factor of 2, scan time $=5 \min 12 \mathrm{~s}$.

\section{fMRI acquisition}

PCASL (Shin et al., 2012) was performed to acquire whole-brain cerebral blood flow $(\mathrm{CBF})$ images: tagging duration $=1.8 \mathrm{~s}, \mathrm{TI}=3 \mathrm{~s}, \mathrm{TE}=12 \mathrm{~ms}$, $\mathrm{TR}=4 \mathrm{~s}$, reps $=66, \mathrm{FOV}=22 \times 22 \mathrm{~cm}$, in-plane matrix size $=64 \times 64$, $265 \mathrm{~mm}$ axial slices with $1 \mathrm{~mm}$ slice gap, scan time $=4 \min 24 \mathrm{~s}$. A single-shot EPI acquisition with GRAPPA factor of 2 was used.

\section{Study design}

Study procedures across experimental sessions and groups are illustrated in Figure 1.

\section{Experimental Session 1 (psychophysical training)}

After providing written consent, subjects completed the FMI. During psychophysical training, subjects were familiarized with 32, $5 \mathrm{~s}$ duration stimuli $\left(35-49^{\circ} \mathrm{C}\right)$ and use of the VAS. Stimuli were delivered to the ventral aspect of the left forearm. We moved the thermal probe to a new location after each stimulus to reduce habituation and/or sensitization. We then administered a $4 \mathrm{~min}$ and $24 \mathrm{~s}$ series of alternating $49^{\circ} \mathrm{C}(12 \mathrm{~s}$ plateau) and $35^{\circ} \mathrm{C}$ ( $12 \mathrm{~s}$ plateau) stimulation to the back of the left calf, identical to the "heat" paradigm used in subsequent MRI experimental sessions. This procedure allowed us to identify individuals either too sensitive to tolerate the stimulus required for $\mathrm{CBF}$ assessment or too insensitive $(\mathrm{VAS}$ ratings $<2$ ) to reliably produce detectable pain-related brain activation (Zeidan et al., 2011).

\section{Experimental Session 2 (MRI Session A)}

In MRI Session A, participants were positioned in the MRI scanner, with a respiratory transducer (TSD 201; Biopac Systems) placed around the chest and a pulse oximeter (OXY-MRI-SPO2; Biopac Systems) placed on the left index finger. Subjects positioned their right leg on the thermal probe that was attached to a custom-made force transducer coupled to a digital chart recorder (AD Instruments). This allowed subjects to freely withdraw their leg from the stimulus in the unlikely event of a probe malfunction and provided investigators evidence that subjects' legs were continuously maintained on the thermal probe.

During MRI acquisition, subjects were instructed to not move and keep their eyes closed. We first acquired a structural MRI scan $(\sim 5 \mathrm{~min})$, which allowed subjects to acclimate to the scanner environment before the initiation of functional neuroimaging. Next, we acquired four total series of PCASL images ( 4 min 24 s) in MRI Session A. We administered two "neutral" and two "heat" series in an alternating fashion counterbalanced across subjects during PCASL acquisition (i.e., heat-neutral-heatneutral or neutral-heat-neutral-heat). The "neutral" series consisted of sustained, innocuous warm $35^{\circ} \mathrm{C}$ stimulation. The "heat" series included a total of ten $12 \mathrm{~s}$ plateaus of $49^{\circ} \mathrm{C}$ (rise/fall rate $=5^{\circ} \mathrm{C} / \mathrm{s}$ ) interleaved between eleven $8 \mathrm{~s}$ periods of $35^{\circ} \mathrm{C}$ stimulation. This approach is similar to the alternating stimuli used in early positron emission tomography studies (Coghill et al., 1994; Coghill et al., 1999) and allows for the delivery of frankly noxious stimuli over relatively long periods of time without producing tissue damage or inducing significant habituation/desensitization. The first $24 \mathrm{~s}$ of the "heat" series consisted of sustained $35^{\circ} \mathrm{C}$ stimulation and was used for MRI equilibration. We obtained VAS pain intensity and unpleasantness ratings after each PCASL series. The thermal probe was moved to a new location on the right calf after each series to further reduce habituation and/or sensitization. Functional neuroimaging data from MRI Session A is not presented in the present manuscript.

Experimental Sessions 3-6 (group training/conditioning sessions) Placebo conditioning regimen. Subjects in the placebo group participated in an extension of a validated $4 \mathrm{~d}$ placebo conditioning regimen (Price et al., 1999; Colloca et al., 2010). Before the start of the placebo conditioning regimen, participants were told that they were participating in an "experimental trial of a new formulation of a topical, local anesthetic being tested for its pain reducing effects over time." They were told that the drug's name is "lidocaine" and that it "has been proven effective at progressively reducing pain after multiple applications in preliminary studies at other universities."

In placebo conditioning Sessions 1-4, a "heat" series (i.e., 10, $12 \mathrm{~s}$ plateaus of $49^{\circ} \mathrm{C}$ ) was first delivered to untreated skin (Series A). Next, a laboratory technician wearing a white laboratory coat and blue medical gloves administered the placebo cream (petrolatum jelly) to the back of the left calf. After $10 \mathrm{~min}$, the cream was removed and a second "heat" series was delivered to the treated skin region (Series B). Importantly, to enhance placebo conditioning, the stimulus temperatures delivered to the treated skin were covertly reduced from $49^{\circ} \mathrm{C}$ in a progressive fashion across sessions (placebo conditioning Session $1=48^{\circ} \mathrm{C}$, placebo conditioning Session 2 and $3=47^{\circ} \mathrm{C}$, and placebo conditioning Session $4=$ $46.5^{\circ} \mathrm{C}$ ). Pain intensity and pain unpleasantness ratings were collected after each series (not presented here). To match the stimuli delivered in the meditation-training regimen (see "Mindfulness meditation training regimen"), we presented an audiorecording of the MRI scanner sounds in the last 10 min of placebo conditioning Session 3. In placebo conditioning Session 4, we instructed subjects to lie down in the supine position (during cream application/removal) during an audio recording of the sounds of the scanner during the entire 20 min session.

Mindfulness meditation training regimen. Similar to previous studies (Zeidan et al., 2010a,b,c; Zeidan et al., 2011; Zeidan et al., 2014), subjects in the meditation group participated in 4 separate days $(20$ $\mathrm{m} / \mathrm{d}$ ) of mindfulness-based mental training. Subjects were informed that meditation training was secular and taught as the cognitive practice of mindfulness meditation. Across all of the meditation training sessions, subjects were instructed to focus on the changing sensations of the breath while employing a non-evaluative cognitive state. Time providing guided meditative instructions was progressively reduced across meditation training days to allow subjects to meditate in silence (Zeidan et al., 2010a,b,c; Zeidan et al., 2011; Zeidan et al., 2014). In each session before meditation training, we paralleled the thermal stimuli that the placebo group received during placebo conditioning (see "Placebo conditioning regimen"). This was done to reduce potential habituation and/or sensitization effects. Importantly, there was no conditioning component associated with these temperature reductions. Accordingly, subjects in the mindfulness meditation group did not meditate before or during thermal stimulation procedures administered in the meditation intervention.

In each meditation training session, mindfulness-based instructions emphasized acknowledging arising thoughts, feelings, and/or emotions without judgment or emotional reaction and to "simply return their attention back to the breath" sensation whenever such discursive events occurred. Furthermore, subjects were taught that perceived sensory and affective events were "momentary" and "fleeting" and did not require further interpretation or evaluation. In meditation training Session 1, subjects were instructed to focus on the breath sensations occurring "at the tip of the nose." In meditation training Session 2, we instructed participants to expand their focus to the "full flow of the breath," including bodily sensations (e.g., rise and fall of the abdomen and chest). On meditation training day 3 , the same basic principles of the previous sessions were reiterated. An audio recording of MRI scanner sounds was introduced during the last $10 \mathrm{~min}$ of meditation training to better familiarize subjects with meditating in an MRI environment. On the final training session (day 4), subjects received minimal meditation instruction and were required to lie in the supine position and meditate during an audio recording of the MRI sounds to better simulate the scanner 
environment. Contrary to traditional mindfulness-based training programs, subjects were not instructed to practice outside of training.

Sham mindfulness meditation training regimen. The main purpose of the sham mindfulness meditation intervention was to lead subjects to believe they were practicing mindfulness meditation without the instructions related to mindfully attending to the breath in a nonevaluative manner (Zeidan et al., 2010b). This regimen was designed so that the only difference between the mindfulness meditation and sham mindfulness meditation group's training was the mindfulness meditation group's explicit mindfulness-based instructions (e.g., practicing mindful attention to the breath; non-evaluative appraisal of discursive sensory events).

As previously (Zeidan et al., 2010b), participants in the sham mindfulness meditation group were told that they were randomly assigned to the mindfulness meditation group. Subjects were instructed that meditation training was secular and taught as the cognitive practice of mindfulness meditation. In each of the four training sessions $(20 \mathrm{~m} / \mathrm{d})$, subjects were instructed to close their eyes, and to take a deep breath "as we sit here in meditation" every 2-3 min (Zeidan et al., 2010b). All other aspects of the sham mindfulness meditation intervention (i.e., body position, intervention room, facilitator; time spent providing instructions; eyes closed) matched the mindfulness meditation-training regimen. To parallel the mindfulness meditation-training regimen, an audio recording of MRI scanner sounds was introduced during the last $10 \mathrm{~min}$ of training Session 3. On the final training session (day 4), subjects received minimal instructions but were required to lie in the supine position and "meditate" during an audio recording of the MRI sounds. To better control for habituation and/or sensitization effects that may have arisen during the placebo group's thermal stimulation procedures, we administered the same heat stimuli paradigm used for placebo conditioning (Fig. 1) in the sham mindfulness meditation intervention. Importantly, there was no conditioning component associated with these temperature reductions. Accordingly, subjects in the sham mindfulness meditation group did not practice sham mindfulness meditation before or during thermal stimulation procedures administered in the sham mindfulness meditation intervention.

Book listening control regimen. The control group listened to an audio recording of The Natural History and Antiquities of Selborne (White, $1908)$ across 4 ds $(20 \mathrm{~m} / \mathrm{d})$. The Natural History and Antiquities of Selborne has been previously used and validated as a neutral comparison regimen for guided relaxation interventions (Cropley et al., 2007; Ussher et al., 2009). Audio recordings were custom designed to continue from where the recording ended from the previous book-listening session. Therefore, subjects whom successfully completed the book-listening regimen listened, in total, to $80 \mathrm{~min}$ of the Natural History and Antiquities of Selborne.

This group was used to control for facilitator attention, meditation/ placebo training setting, placebo-based thermal stimulation procedures and the time elapsed in the other interventions. Subjects were not allowed to sleep, use their phones, or talk to the experimenter during book listening. In control Session 3, we introduced the sounds of the scanner in the last 10 min of book listening. In book listening Session 4, subjects were instructed to lie in the supine position and listen to the audio book and sounds of the scanner. We administered the same heat stimuli as used for placebo conditioning. This was done to reduce potential habituation and/or sensitization effects. Importantly, there was no conditioning component associated with these temperature reductions. Accordingly, subjects in the control group did not listen to Natural History and Antiquities of Selborne before or during thermal stimulation procedures.

\section{Experimental Session 7 (MRI Session B)}

In MRI Session B, subjects were positioned identically to MRI Session A with their right leg placed on the thermal stimulator.

Pre-manipulation (Rest) (first 4 PCASL Series $=$ Pre)

During the "pre-manipulation" condition, all subjects were instructed to not move and keep their eyes closed. Subjects underwent four PCASL series. During these series, participants received two "heat" and two "neutral" stimulus series. These were delivered in an alternating fashion counterbalanced across subjects (i.e., neutral-heat-neutral-heat or heat-neutral-heat-neutral).

Anatomical scan. An anatomical scan was then conducted after the first four-PCASL series.

\section{Manipulation instructions}

Placebo group. After the first four thermal series, we applied the placebo cream. After $10 \mathrm{~min}$ (including anatomical acquisition), we removed the placebo cream before administering the last four-PCASL series.

Mindfulness meditation and sham mindfulness meditation group. After the first four thermal series and before anatomical acquisition, subjects in the mindfulness meditation and sham mindfulness meditation group were instructed to "begin meditating" and "to continue to meditate till the end of the experiment."

Control group. After the first four thermal series and before anatomical acquisition, subjects in the control group received standard instructions to not move and "keep eyes closed."

\section{Post-manipulation (last 4 PCASL series $=$ Post)}

As in the pre-manipulation, subjects received four PCASL scans in which they received two "heat" and two "neutral" stimulation series in an alternating fashion, counterbalanced across subjects (i.e., neutral-heatneutral-heat or heat-neutral-heat-neutral). Pain ratings were collected after each "heat" and "neutral" PCASL series. Subjects completed the FMI after completing their scanning session.

\section{Analysis of behavioral data}

Behavioral data were analyzed with SPSS 19.0 software (IBM, Armonk, New York). In all ANOVAs, significant $(p<0.05)$ main effects and interactions were investigated with planned post hoc tests comparing the percent change in behavioral outcomes between the mindfulness meditation and the three comparison groups (Toothaker, 1993; Cohen and Lea, 2004).

\section{Pain ratings}

Psychophysical assessment of pain from MRI Sessions A and B were analyzed separately (Zeidan et al., 2011). In MRI Session A, group differences in pain intensity and unpleasantness ratings were examined with a single-factor ANOVA. In MRI Session B, a two-factor ANOVA tested the primary hypothesis that mindfulness meditation would produce greater reductions in pain intensity and unpleasantness ratings compared with pre-manipulation, placebo analgesia, sham mindfulness-related pain relief, and the control manipulation. To confirm the validity of our cognitive manipulations, we conducted additional post hoc analyses comparing the percent change in pain ratings between the control and cognitive manipulation groups.

\section{Mindfulness inventory}

A 2 (pre-intervention) $\times 4$ (group) repeated-measures $(\mathrm{RM})$ ANOVA tested the hypothesis that mindfulness meditation training would significantly improve FMI scores from the pre-intervention.

\section{Perceived intervention effectiveness}

A 4 (intervention sessions) $\times 4$ (group) RM ANOVA assessed for changes in "perceived effectiveness" rating scores in each training session and between groups.

\section{Analysis of neuroimaging data}

Calculation of cerebral blood flow. Each 4D series of PCASL images was converted into a single CBF volume. The alternating tag and control images were subtracted to generate a perfusion-weighted series. PCASL is sensitive to subject motion, which may lead to inaccurate CBF maps. To reduce the influence of subject motion on CBF quantification, the PCASL time series data were filtered to remove individual perfusionweighted images with higher motion parameters and perfusion fluctuations that corrupt the final CBF map (Tan et al., 2009). The first volume of the PCASL data was acquired with long recovery time (3 TRs) after presaturation to allow for magnetization recovery. The volume was used to estimate the CSF M0 value and to scale raw perfusion weighted images into a quantitative CBF map according to the general kinetic model 
A

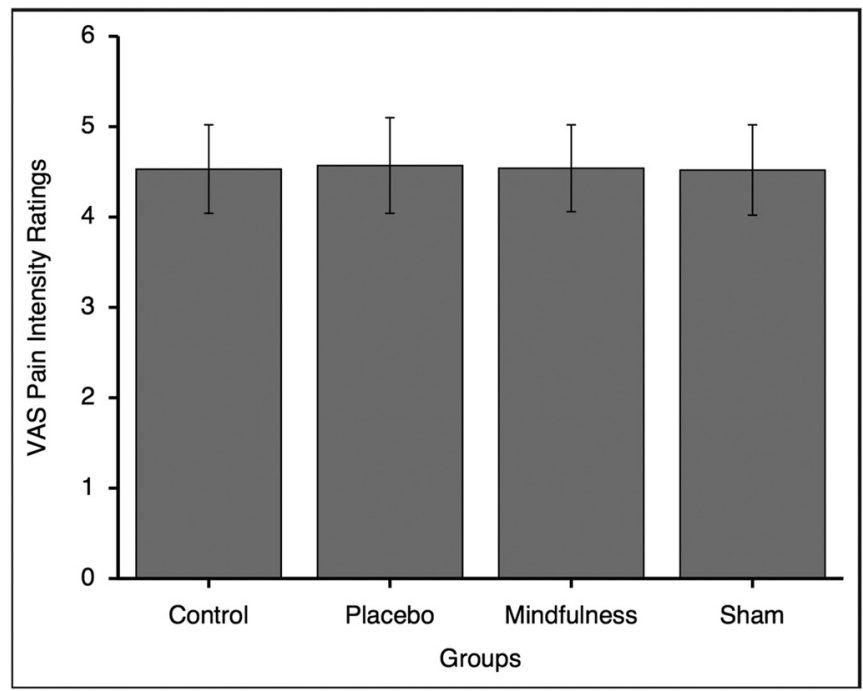

B

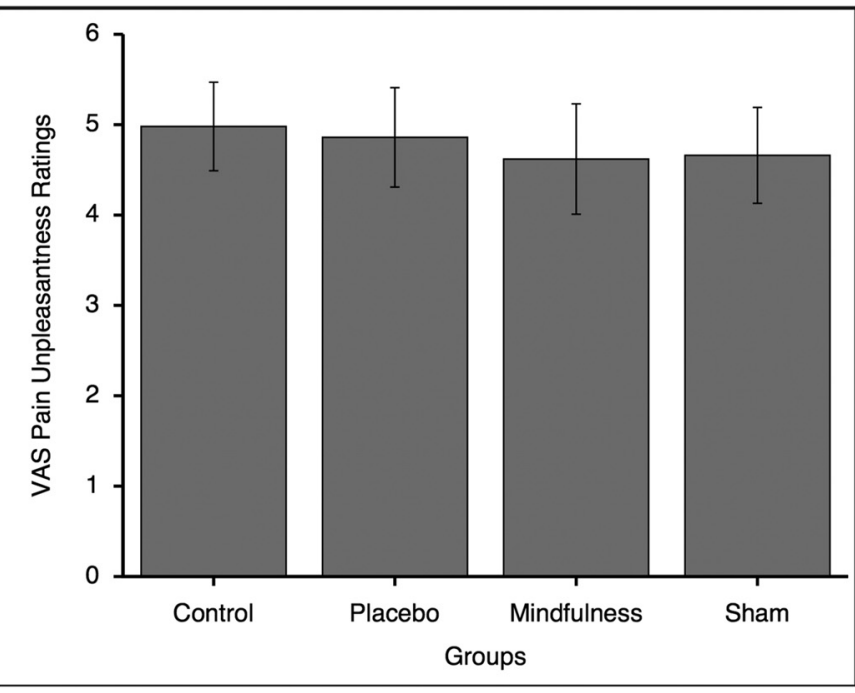

Figure 2. Psychophysical pain ratings (mean \pm SEM) in MRI Session A. There were no significant differences among the mindfulness meditation (mindfulness), sham mindfulness meditation (sham), placebo, or book listening control (control) groups on pain intensity (left; $p=1.00$ ) or pain unpleasantness (right; $p=0.96)$ ratings. $\boldsymbol{A}$, VAS pain intensity ratings. $\boldsymbol{B}$, VAS pain unpleasantness ratings.

(Buxton et al., 1998). Global CBF was calculated from the CBF volume as the mean of all voxels within the brain.

Statistical analyses of regional signal changes within the brain Regional CBF was the dependent variable in the proposed statistical analyses of regional brain signal changes. Brain activation was inferred via significant changes in CBF. The functional image analysis package FSL [Functional Magnetic Resonance Imaging of the Brain (FMRIB) Software Library (Center for FMRIB, University of Oxford, Oxford, UK)] was used for image processing and analyses. Individual CBF volumes derived from PCASL series were first concatenated into a 4D volume for each individual to perform first-level analyses (MRI Session B = 8 -volume series). Functional data were spatially smoothed with a $9 \mathrm{~mm}$ full-width at half-maximum 3D isotropic Gaussian kernel before standard processing within the FEAT module of FSL. Within FEAT, each CBF volume was scaled by its mean global intensity (intensity normalization) to minimize confounds arising from global CBF fluctuations. Because each $\mathrm{CBF}$ volume in the series is temporally independent from adjacent volumes, temporal filtering was not performed.

Each subject's functional images were registered to their structural data using a six-parameter linear 3D transformation. Brain-extracted structural data were transformed into standard stereotaxic space (as defined by Montreal Neurologic Institute) using a 12-parameter affine transformation followed by a nonlinear transformation (Jenkinson et al., 2002; Andersson, 2007a,b). This nonlinear transform then was applied to CBF data.

Statistical analysis of regional signal changes was performed on 4D concatenated CBF data (first-level analyses) using a fixed-effects general linear modeling approach (Woolrich et al., 2001). Random-effects analyses were used to assess activation across individuals. T/F statistic images were Gaussianized and thresholded using clusters determined by a $z>$ 2.3. Corrected cluster significance threshold was set at $p<0.05$ (Worsley et al., 1992). This procedure ensures that the probability of false-positive findings is corrected for multiple comparisons across all brain voxels (Worsley, 2001).

MRI Session A. Functional neuroimaging data from MRI Session A are not presented here.

MRI Session B. The first-level two-factor RM ANOVA was performed for each individual to identify a main effect of stimulation ("heat" vs "neutral") and manipulation (e.g., pre-manipulation vs postmanipulation). A second-level analysis was performed across individuals within each group to identify significant mean effects associated with stimulation level (i.e., pain) and each respective manipulation. A priori third-level ANOVA analyses were conducted to test the hypotheses that these mean effects differ between mindfulness meditation and the comparison groups (Toothaker, 1993; Kirk, 1995).

Conjunction analyses (Nichols et al., 2005) were conducted to identify significant overlapping neural activity between the main effect of mindfulness meditation and comparison groups. To identify the relationship between manipulation-induced pain changes and brain activation in the presence of heat, the four "heat" volumes (two pre-manipulation "heat" volumes vs two post-manipulation "heat" volumes) were concatenated for each subject (Zeidan et al., 2011). Multiple regression analyses were used to assess the relationship between individual differences in manipulation-induced percent changes (pre-manipulation vs postmanipulation) in pain ratings and corresponding brain activation in the presence of "heat" volumes only. The first regressor modeled the mean effect of each respective manipulation compared with the premanipulation condition. The second regressor modeled the percent changes in each subject's pain intensity ratings. Percentage changes for each subject's pain unpleasantness ratings were modeled as the third regressor. To identify variability in brain activity uniquely related to each aspect of pain and independent from the mean effect of manipulation, pain intensity and unpleasantness ratings were orthogonalized to each other and to the mean effect.

The use of perfusion-based MRI is better suited to image steady cognitive states such as meditation compared with other fMRI methods because it allows for the direct quantification of CBF that can lead to better assessment of artifacts related to physiological changes and better control of image quality (Luh et al., 2000). During MRI Session B, significant reductions in respiration rate from pre-manipulation to postmanipulation were detected during mindfulness and sham mindfulness meditation (Table 1). Reductions in respiration rate were likely associated with deeper breathing and presumptive reductions in arterial $\mathrm{pCO}_{2}$ (Kastrup et al., 1999a,b; Abbott et al., 2005; Birn et al., 2009). Such decreases in $\mathrm{pCO}_{2}$ are associated with reductions in CBF values (Kety and Schmidt, 1948; Tancredi et al., 2012). Because white matter blood flow changes are smaller than gray matter changes (Kastrup et al., 1999a), decreased global CBF can lead to artifactual apparent increases in white matter after mean intensity normalization (Coghill et al., 1998). Follow-up visual inspection during quality control analyses of PCASL data revealed that significant increases in white matter activation occurred during mindfulness and sham mindfulness meditation. A simple bivariate regression confirmed that there was a significant relationship between the percent change in respiration rate and $\mathrm{CBF}\left(n=75, R^{2}=\right.$ 

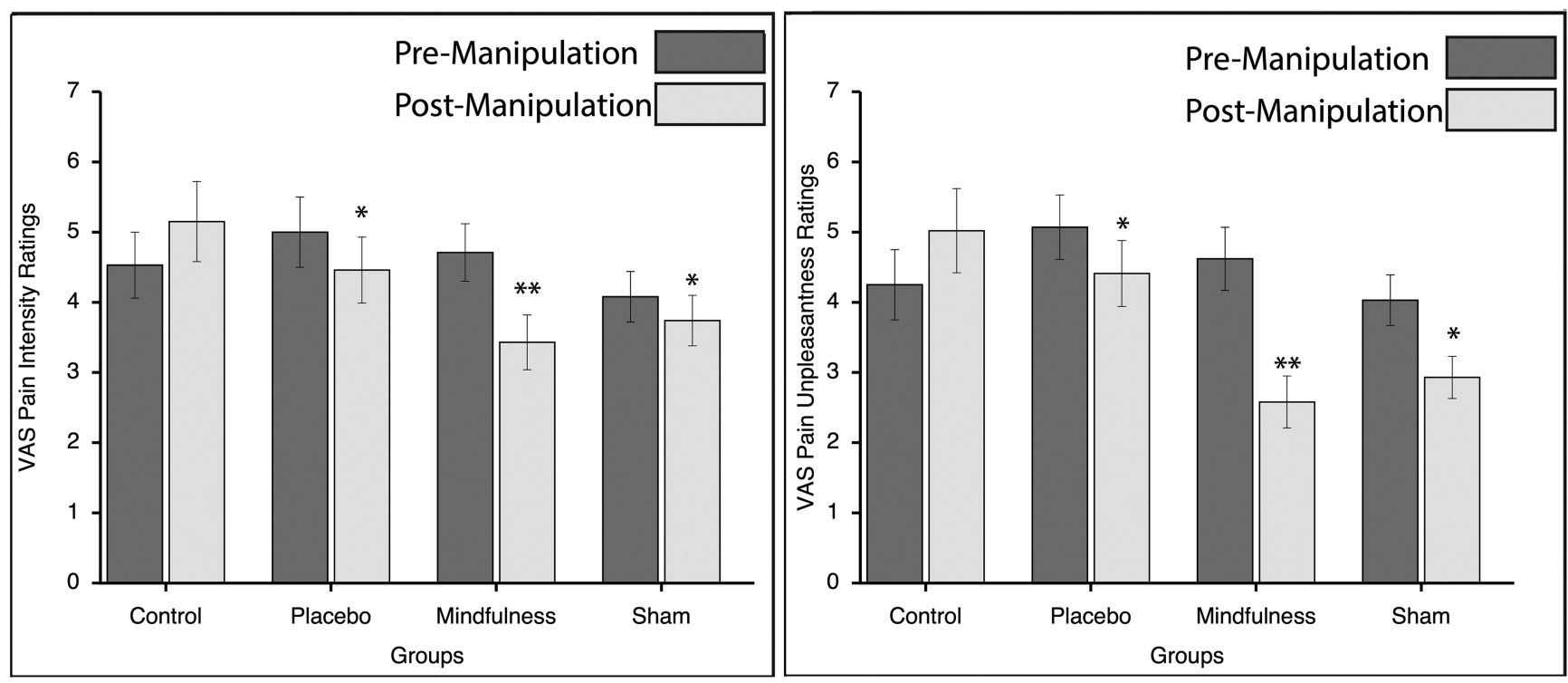

Figure 3. Psychophysical pain ratings (mean \pm SEM) in MRI Session B. Mindfulness meditation produced greater reductions in both pain intensity (left) and pain unpleasantness (right) compared with placebo. **Mindfulness meditation also was significantly $(p<0.05)$ more effective at reducing pain intensity (left) and pain unpleasantness (right) ratings than sham mindfulness meditation and control conditions. *All cognitive manipulations were significantly $(p<0.004)$ more effective at reducing pain intensity and unpleasantness ratings compared with the control group.

$0.24, p<0.001)$. Therefore, in addition to mean intensity normalization of our PCASL data, we first segmented each subject's anatomical data into white matter partial volume maps using the FAST algorithm in FSL (Smith et al., 2004) and extracted their respective white matter values. We then included each individual's respective white matter value as a nuisance covariate of no interest in the first-level analyses in MRI Session B (Fox et al., 2005; Restom et al., 2006; Behzadi et al., 2007; Leber, 2010). Subject-to-subject visual inspections of first-level PCASL analyses confirmed that this technique reduced white matter artifacts.

\section{Analysis of physiological data}

In all ANOVAs examining physiological data, significant $(p<0.05)$ main effects and interactions were investigated with planned post hoc tests comparing the percent change in physiological outcomes between the mindfulness meditation and the three comparison groups (Toothaker, 1993; Cohen and Lea, 2004).

\section{Respiration rate}

A 2 (pre-manipulation vs post-manipulation) $\times 2$ ("heat" vs "neutral") $\times 4$ (group) mixed-model ANOVA tested for changes in respiration rate in MRI Session B. Prior work has demonstrated a positive relationship between pain ratings and respiration rate (Grant and Rainville, 2009; Martin et al., 2012). Therefore, a three-factor ANOVA tested the main effect of group, manipulation, and stimulation level (i.e., "heat," "neutral") on respiration rate. Multiple regression analyses were performed to determine whether respiration rate predicted changes in pain ratings within groups.

Global cerebral blood flow

In MRI Session B, a 2 (pre-manipulation vs post-manipulation) $\times 2$ ("heat" vs "neutral") $\times 4$ (group) mixed-model ANOVA tested for changes in global CBF.

Heart rate

A 2 (pre-manipulation vs post-manipulation) $\times 2$ ("heat" vs "neutral") $\times 4$ (group) mixed-model ANOVA tested for changes in heart rate in MRI Session B.

\section{Results}

\section{Behavioral findings}

Pre-intervention

There were no significant pre-intervention differences among groups for pain intensity $\left(F_{(3,71)}=0.002, p=1.00\right)$ or unpleas- antness $\left(F_{(3,71)}=0.10, p=0.962\right)$ ratings in response to the "heat" series (Fig. 2).

One participant provided a rating of 0.30 (pain intensity and unpleasantness) in response to a "neutral" series. All other subjects provided a " 0 " to "neutral" series. Therefore, there were no significant group differences for pain intensity $\left(F_{(3,71)}=0.98, p=\right.$ $0.406)$ or pain unpleasantness $\left(F_{(3,71)}=0.98, p=0.406\right)$ ratings in response to the "neutral" series.

\section{Post-intervention}

Mindfulness meditation produces greater pain relief than placebo and sham mindfulness meditation.

\section{Pain intensity ratings}

All groups exhibited a significant change in pain intensity ratings from pre-manipulation to post-manipulation in response to "heat" series $\left(F_{(1,71)}=10.06, p=0.002, \eta_{p}^{2}=0.12\right.$; Fig. 3). The significant group $\times$ manipulation interaction on pain intensity $\left(F_{(3,71)}=9.96, p<0.001, \eta_{\mathrm{p}}^{2}=0.30\right)$ was associated with the significant decrease in pain intensity ratings during mindfulness meditation $\left(-27 \% ; F_{(1,16)}=13.00, p=\right.$ $\left.0.002, \eta_{\mathrm{p}}^{2}=0.45\right)$, placebo $\left(-11 \% ; F_{(1,18)}=5.74, p=0.028, \eta_{\mathrm{p}}^{2}\right.$ $=0.24)$, and sham mindfulness meditation $\left(-8 \% ; F_{(1,19)}=\right.$ 4.67, $\left.p=0.044, \eta_{\mathrm{p}}^{2}=0.20\right)$ and the significant pain intensity increase $\left(+14 \% ; F_{(1,18)}=7.52, p=0.013, \eta_{\mathrm{p}}^{2}=0.30\right)$ during the control condition. There was no significant main effect of group $\left(F_{(3,71)}=1.20, p=0.315\right)$.

To interpret the significant manipulation $\times$ group interaction, we calculated and compared the percent change in pain intensity and unpleasantness ratings between the mindfulness meditation and comparison groups (Toothaker, 1993). This approach was used to test the hypothesis that mindfulness meditation would produce greater reductions in pain ratings compared with the comparison groups. Our hypotheses were supported because mindfulness-meditation-related pain intensity reductions (Fig. 3) were significantly greater than placebo analgesia ( $p=0.032)$, sham mindfulness-meditationrelated pain relief $(p=0.030)$, and the control condition $(p<$ $0.001)$. Importantly, all cognitive manipulations significantly 
reduced pain intensity ratings compared with the control condition (placebo conditioning, $p=0.001$; sham mindfulness meditation, $p=0.003$; Fig. 3 ).

Two participants provided nonzero VAS ratings to a "neutral" series and all other subjects provided a " 0 " to "neutral" series. There was no significant pre-manipulation versus postmanipulation $\left(F_{(1,71)}=1.55, p=0.217\right)$ or pre-manipulation versus post-manipulation $\times$ group interaction $\left(F_{(3,71)}=0.68\right.$, $p=0.565)$ on pain intensity ratings in response to "neutral" series.

Pain unpleasantness ratings

There was a significant main effect of manipulation $\left(F_{(1,71)}=\right.$ $21.08, p<0.001, \eta_{\mathrm{p}}^{2}=0.23$ ) on pain unpleasantness ratings in response to "heat" series. Post hoc tests found that mindfulness meditation significantly reduced pain unpleasantness ratings $\left(-44 \% ; F_{(1,16)}=24.26, p<0.001, \eta_{\mathrm{p}}^{2}=0.60\right)$ compared with pre-manipulation. The placebo condition exhibited a trend toward a significant reduction $(-13 \%)$ in pain unpleasantness ratings $\left(F_{(1,18)}=4.24, p=0.054, \eta_{\mathrm{p}}^{2}=0.19\right)$ and sham mindfulness meditation significantly reduced $(-27 \%)$ pain unpleasantness ratings $\left(F_{(1,19)}=11.46, p=0.003, \eta_{\mathrm{p}}^{2}=0.38\right)$. There was also a significant increase $(+18 \%)$ in pain unpleasantness ratings $\left(F_{(1,18)}=9.39, p=0.007, \eta_{\mathrm{p}}^{2}=0.34\right)$ ratings from pre-manipulation to post-manipulation during the control condition (Fig. 3). There was no significant main effect of group $\left(F_{(3,71)}=2.62, p=0.058\right)$.

There was a significant manipulation $\times$ group interaction $\left(F_{(3,71)}=12.44, p<0.001, \eta_{\mathrm{p}}^{2}=0.34\right)$. A priori $t$ tests were conducted to investigate this significant interaction and to test the hypothesis that mindfulness meditation reduces pain unpleasantness ratings more than the comparison groups. Mindfulness-meditation-related pain unpleasantness reductions (Fig. 3) were significantly greater than placebo $(p<0.001)$, sham mindfulness meditation $(p=0.043)$, and the control condition $(p<0.001)$. Similar to the post hoc analyses on pain intensity ratings, placebo cream $(p<0.001)$ and sham mindfulness meditation $(p<0.001)$ significantly reduced pain unpleasantness ratings when compared to the control condition (Fig. 3).

Two participants provided nonzero VAS ratings to a "neutral" series and all other subjects to a "0" to a "neutral" series. There was no significant pre-manipulation vs post-manipulation $\left(F_{(1,71)}=1.81, p=0.183\right)$ or pre-manipulation vs post-manipulation $\times$ group interaction $\left(F_{(3,71)}=0.64, p=0.589\right)$ on pain unpleasantness ratings in response to "neutral" series.

\section{Four days of mindfulness meditation training significantly} increased mindfulness

There was no significant main effect of group $\left(F_{(3,71)}=0.29, p=\right.$ 0.833 ) on FMI ratings, demonstrating that there were no significant baseline (pre-intervention) differences. The significant main effect of pre-intervention versus post-intervention $\left(F_{(1,71)}=\right.$ 4.26, $\left.p=0.043, \eta_{\mathrm{p}}^{2}=0.06\right)$ and the significant $4 \mathrm{~d}$ preintervention versus $4 \mathrm{~d}$ post-intervention $\times$ group interaction $\left(F_{(3,71)}=5.99, p=0.001, \eta_{\mathrm{p}}^{2}=0.20\right)$ was associated with the significant mindfulness meditation training induced $16 \%$ increase in FMI scores compared with the placebo $(p=0.003$; $-3 \%)$, sham mindfulness meditation $(p=0.006 ;+0.03 \%)$, and control $(p=0.026 ;+2 \%)$ groups (Table 1$)$.

No perceived differences in intervention effectiveness between the mindfulness and sham mindfulness meditation groups

There was no significant main effect between groups on "perceived intervention effectiveness" $\left(F_{(3,71)}=0.92, p=0.434\right)$. The
Table 2. Perceived intervention effectiveness ratings (mean \pm SEM) across sessions

\begin{tabular}{llllll}
\hline Group & IS 1 & IS & IS 3 & IS 4 & Total \\
\hline Control & $2.38(0.53)$ & $3.61(0.63)$ & $2.93(0.58)$ & $3.19(0.61)$ & $3.03(0.54)$ \\
Placebo & $1.89(0.45)$ & $3.48(0.46)$ & $4.19(0.58)$ & $6.08(0.56)$ & $3.91(0.44)$ \\
Mindfulness & $3.32(0.53)$ & $3.96(0.66)$ & $4.28(0.51)$ & $4.23(0.54)$ & $3.95(0.52)$ \\
Sham & $3.75(0.35)$ & $4.21(0.40)$ & $3.53(0.35)$ & $3.93(0.36)$ & $3.85(0.32)$ \\
\hline
\end{tabular}

There were no significant differences in perceived intervention effectiveness between the mindfulness and shammindfulness meditation (sham) groups across intervention sessions (IS). In contrast, the placebo conditioning group's perceived effectiveness of the placebo cream increased more rapidly over time relative the time course of the other group's respective perceived intervention effectiveness ratings.

main effect of session $\left(F_{(3,213)}=23.76, p<0.001, \eta_{\mathrm{p}}^{2}=0.25\right)$ was associated with increasing effectiveness ratings across time (Table 2). A significant session $\times$ group interaction $\left(F_{(9,213)}=9.99, p<\right.$ $0.001, \eta_{\mathrm{p}}^{2}=0.30$ ) was associated with more rapid increases in perceived effectiveness of the placebo manipulation relative to the other group's manipulations (Table 2).

Importantly, the sham mindfulness meditation intervention was effective at leading subjects to believe they were meditating because there were no significant differences in the average perceived "meditative effectiveness" ratings between the genuine mindfulness meditation and sham mindfulness meditation groups across each intervention (Table $2 ; p>0.88$ ).

\section{Neuroimaging findings}

Pain-related brain activation

Compared with neutral $\left(35^{\circ} \mathrm{C}\right)$ stimulation, noxious $\left(49^{\circ} \mathrm{C}\right)$ stimulation produced activation in the SI corresponding to the stimulation site, midcingulate cortex, anterior/posterior insula, frontal operculum, SII, and supplementary motor area (SMA) and deactivation in the posterior cingulate cortex (PCC) and medial prefrontal cortex (mPFC) across all four groups (Fig. 4; see Table 3 for corresponding brain coordinates). Noxious stimulation also produced activation in the thalamus and cerebellum in the placebo, sham mindfulness meditation, and control groups. Post hoc assessments revealed significantly greater "heat"-related activation in left DLPFC in the control, placebo, and sham mindfulness meditation groups when compared to the mindfulness meditation group (Fig. 4). This effect is likely driven by the significantly larger deactivation in the DLPFC in the meditation group.

\section{Mindfulness meditation deactivates the thalamus and periaqueductal gray matter}

The cognitive state of mindfulness meditation significantly deactivated brain regions that facilitate low-level sensory and nociceptive processing including the thalamus and periaqueductal gray matter (PAG) compared with rest and the main effects of placebo and sham mindfulness meditation (Figs. 5, 6; see Table 3 for corresponding brain coordinates).

\section{Mindfulness meditation activates different brain mechanisms} from placebo

Compared with the main effect of the placebo manipulation, mindfulness meditation produced greater activation in brain regions that mediate the cognitive control of pain, including the ACC, bilateral anterior insula, and putamen (Fig. 5). Consistent with the mindfulness-based cognitive practice of directing attention toward the breath (Zeidan et al., 2011), significant activation corresponding to the somatotopic representation of the nose (Gastl et al., 2014) and mouth (Penfield and Boldrey, 1937) in the SI was detected when compared to the pre-manipulation condition and placebo. In contrast, the main effect of placebo pro- 

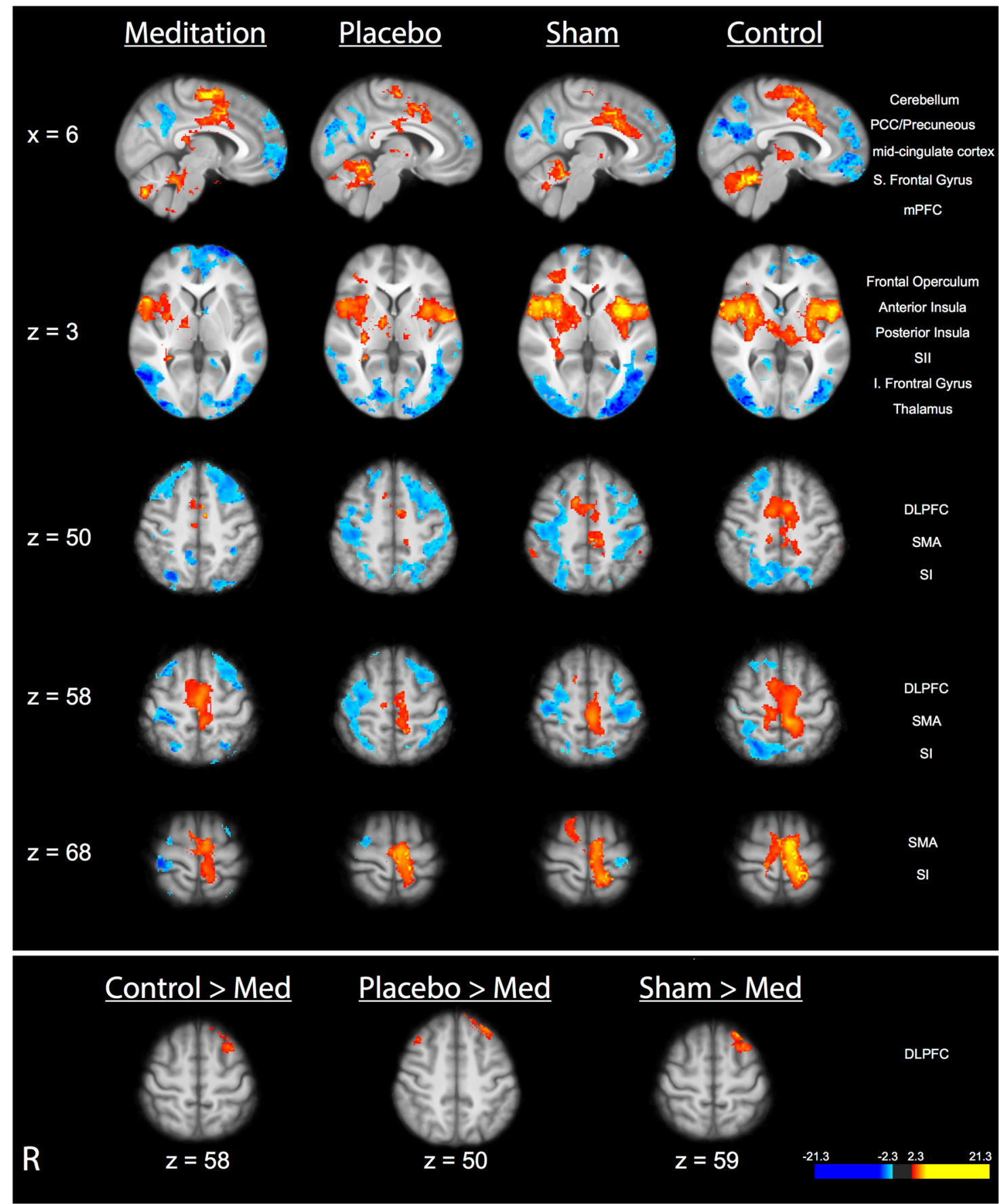

Figure 4. Brain activations and deactivations associated with the main effect of pain in each group in MRI Session B. Top, In all four groups, there was significant activation in the SI corresponding to the stimulation site, thalamus, cerebellum, midcingulate cortex, anterior/posterior insula, frontal operculum, SII, and SMA. Significant deactivations were detected in the $\mathrm{mPFC}, \mathrm{PCC} /$ precuneous, and superior (S) frontal gyrus in all four groups. Bottom, Group comparisons revealed significantly greater activation in the left DLPFC in the placebo, sham mindfulness meditation, and control group compared with the mindfulness meditation group. Slice locations correspond to standard stereotaxic space.

duced greater activation in the bilateral DLPFC, PAG, thalamus, cerebellum, PCC, and superior frontal gyrus when compared to mindfulness meditation. It is important to note that many differences between mindfulness meditation and placebo were the result of greater deactivation in one condition compared with the other (Fig. 5). Despite the differences in activation between mindfulness meditation and placebo, one region at the border between the ventral insula and medial temporal lobe was activated in both conditions.
Neural correlates of mindfulness meditation and placebo conditioning-based analgesia are different

Largely consistent with our previous study (Zeidan et al., 2011), mindfulness-based pain intensity reductions were associated with greater activation in the subgenual (sgACC), bilateral OFC, right putamen, and anterior insula (Fig. $7 A$; see Table 3 for corresponding brain coordinates). After accounting for the variance explained by brain activity related to pain intensity reductions, greater reductions in pain unpleasantness ratings were associated 
Table 3. Brain coordinates corresponding to cerebral blood flow activations/deactivations in Figures 4, 5, 6, and 7

\begin{tabular}{|c|c|c|c|}
\hline & Region & Zscore & $(x, y, z)$ \\
\hline \multicolumn{4}{|c|}{ Figure 4: MRI B: Main effect pain } \\
\hline \multicolumn{4}{|c|}{ Mindfulness meditation group } \\
\hline \multirow[t]{8}{*}{ Activation } & Right cerebellum & 5.60 & $4,-74,-36$ \\
\hline & Left cerebellum & 3.50 & $-12,-64,-26$ \\
\hline & Midcingulate cortex & 3.60 & $6,-4,38$ \\
\hline & Right anterior insula & 3.20 & $34,20,2$ \\
\hline & Right SII & 3.51 & $52,4,2$ \\
\hline & Right thalamus & 3.55 & $12,-10,2$ \\
\hline & SMA & 2.78 & $-4,-4,68$ \\
\hline & SI & 3.35 & $-8,-44,68$ \\
\hline \multirow[t]{3}{*}{ Deactivation } & S. frontal gyrus & 3.05 & $6,56,32$ \\
\hline & PCC/precuneous & 3.44 & $6,-48,30$ \\
\hline & $\mathrm{mPFC}$ & 4.44 & $6,52,-8$ \\
\hline \multicolumn{4}{|l|}{ Placebo group } \\
\hline \multirow[t]{13}{*}{ Activation } & Right cerebellum & 4.40 & $18,-42,-22$ \\
\hline & Left cerebellum & 3.05 & $-24,-66,-30$ \\
\hline & Midcingulate cortex & 3.60 & $6,-14,32$ \\
\hline & Right anterior insula & 3.12 & $32,18,2$ \\
\hline & Left anterior insula & 3.92 & $-34,12,2$ \\
\hline & Right posterior insula & 3.30 & $38,-10,2$ \\
\hline & Left posterior insula & 3.18 & $-36,-20,2$ \\
\hline & Left SII & 4.85 & $-50,-4,2$ \\
\hline & Right SII & 4.00 & $50,4,2$ \\
\hline & Left thalamus & 3.48 & $-12,-20,2$ \\
\hline & Right thalamus & 3.58 & $8,-6,2$ \\
\hline & SMA & 3.56 & $-4,-10,68$ \\
\hline & SI & 3.52 & $-12,-44,68$ \\
\hline Deactivation & PCC/precuneous & 4.00 & $6,-52,30$ \\
\hline \multicolumn{4}{|c|}{ Sham-mindfulness meditation group } \\
\hline \multirow[t]{10}{*}{ Activation } & Right cerebellum & 4.51 & $4,50,-10$ \\
\hline & Left cerebellum & 4.81 & $-4,-48,-12$ \\
\hline & Midcingulate cortex & 6.16 & $-4,-4,38$ \\
\hline & Frontal operculum & 3.51 & $38,22,2$ \\
\hline & Right anterior insula & 7.00 & $40,10,2$ \\
\hline & Left anterior insula & 6.17 & $-38,4,2$ \\
\hline & Left SII & 3.95 & $-56,-2,6$ \\
\hline & Right SII & 4.87 & $54,4,6$ \\
\hline & SMA & 4.02 & $-6,-8,68$ \\
\hline & SI & 3.82 & $-10,-46,68$ \\
\hline \multirow[t]{3}{*}{ Deactivation } & S. frontal gyrus & 3.24 & $6,52,30$ \\
\hline & $\mathrm{PCC} /$ precuneous & 4.37 & $6,-54,36$ \\
\hline & $\mathrm{mPFC}$ & 3.16 & $6,58,-10$ \\
\hline \multicolumn{4}{|l|}{ Control group } \\
\hline \multirow[t]{10}{*}{ Activation } & Right cerebellum & 5.86 & $12,-60,-22$ \\
\hline & Left cerebellum & 4.17 & $-20,-66,-28$ \\
\hline & Midcingulate cortex & 4.12 & $6,-6,44$ \\
\hline & Frontal operculum & 4.45 & $34,26,6$ \\
\hline & Right anterior insula & 6.96 & $34,6,6$ \\
\hline & Left anterior insula & 5.10 & $-34,8,6$ \\
\hline & Left SII & 5.32 & $-54,2,6$ \\
\hline & Right SII & 5.33 & $48,2,6$ \\
\hline & SMA & 6.64 & $-6,-6,68$ \\
\hline & SI & 4.14 & $-12,-42,68$ \\
\hline \multirow[t]{3}{*}{ Deactivation } & S. frontal gyrus & 4.27 & $6,54,32$ \\
\hline & $\mathrm{PCC} /$ precuneous & 4.10 & $0,-54,24$ \\
\hline & $\mathrm{mPFC}$ & 4.11 & $6,58,-2$ \\
\hline \multicolumn{4}{|c|}{ Control $>$ mindfulness meditation } \\
\hline Activation & DLPFC & 4.10 & $-34,14,58$ \\
\hline \multicolumn{4}{|c|}{ Placebo $>$ mindfulness meditation } \\
\hline Activation & DLPFC & 3.82 & $-26,28,58$ \\
\hline \multicolumn{4}{|c|}{ Sham-mindfulness meditation $>$ mindfulness meditation } \\
\hline Activation & DLPFC & 4.65 & $\begin{array}{l}-30,18,58 \\
\text { (Table Continues) }\end{array}$ \\
\hline
\end{tabular}


Table 3. Continued

\begin{tabular}{|c|c|c|c|}
\hline & Region & Zscore & $(x, y, z)$ \\
\hline \multicolumn{4}{|c|}{ Figure 5: Mri B: Main effect of mindfulness meditation, placebo and comparisons } \\
\hline \multicolumn{4}{|c|}{ Main effect of mindfulness meditation } \\
\hline \multirow[t]{9}{*}{ Activation } & ACC & 5.10 & $2,30,20$ \\
\hline & Left putamen & 3.05 & $-20,8-8$ \\
\hline & Right anterior insula & 3.25 & $38,18,-8$ \\
\hline & Left anterior insula & 3.09 & $-38,6,-8$ \\
\hline & Left parietal operculum/SII & 2.71 & $-56,-10,14$ \\
\hline & Right parietal operculum/SII & 3.18 & $56,-8,14$ \\
\hline & Right S1 & 3.19 & $64,0,16$ \\
\hline & Left SI & 3.16 & $-64,0,16$ \\
\hline & Right SI & 3.83 & $50,-16,40$ \\
\hline \multirow[t]{3}{*}{ Deactivation } & Right cerebellum & 6.85 & $30,-80,-32$ \\
\hline & Left DLPFC & 5.81 & $-34,32,40$ \\
\hline & Right DLPFC & 8.66 & $24,36,40$ \\
\hline \multicolumn{4}{|c|}{ Main effect of placebo } \\
\hline Activation & Left anterior insula & 2.85 & $-34,8,-14$ \\
\hline \multirow[t]{2}{*}{ Deactivation } & $\mathrm{ACC}$ & 6.25 & $6,-4,46$ \\
\hline & $\mathrm{PCC}$ & 5.44 & $8,-34,40$ \\
\hline \multicolumn{4}{|c|}{ Mindfulness meditation $>$ placebo } \\
\hline \multirow[t]{5}{*}{ Activation } & $\mathrm{ACC}$ & 3.23 & $6,26,32$ \\
\hline & $\mathrm{PCC}$ & 2.84 & $6,-32,38$ \\
\hline & Right putamen & 4.39 & $24,2,8$ \\
\hline & Left putamen & 3.10 & $-22,4,8$ \\
\hline & Right inferior frontal gyrus & 3.08 & $46,26,8$ \\
\hline \multirow{7}{*}{ Activation } & Right cerebellum & 3.86 & $6,-62,-18$ \\
\hline & Left cerebellum & 4.14 & $-6,-62,-18$ \\
\hline & Left thalamus & 5.75 & $-4,-20,6$ \\
\hline & Right thalamus & 4.63 & $8,-22,6$ \\
\hline & PAG & 2.96 & $0,-28,-8$ \\
\hline & Left DLPFC & 3.82 & $-36,30,40$ \\
\hline & Right DLPFC & 4.51 & $34,38,40$ \\
\hline \multicolumn{4}{|c|}{ Conjunction: Mindfulness meditation + placebo } \\
\hline Activation & Left anterior insula & 2.84 & $-36,8,-12$ \\
\hline \multicolumn{4}{|c|}{$\begin{array}{l}\text { Figure 6: MRI B: Main effect of mindfulness meditation, } \\
\text { sham-mindfulness meditation and comparisons }\end{array}$} \\
\hline \multicolumn{4}{|c|}{ Main effect of sham-mindfulness meditation } \\
\hline \multirow[t]{3}{*}{ Activation } & Left putamen/globus pallidus & 4.31 & $-20,8,-6$ \\
\hline & Right putamen/globus pallidus & 2.90 & $20,6,-6$ \\
\hline & Right SI & 5.56 & $52,-8,36$ \\
\hline \multirow[t]{6}{*}{ Deactivation } & ACC & 4.00 & $6,38,-2$ \\
\hline & Superior frontal gyrus & 4.88 & $6,50,40$ \\
\hline & PCC/precuneous & 8.82 & $6,-56,28$ \\
\hline & Right cerebellum & 6.61 & $6,-62,-28$ \\
\hline & Left cerebellum & 5.91 & $-6,-64,-26$ \\
\hline & Left DLPFC & 4.07 & $-30,28,36$ \\
\hline Mindfulness meditati & & & \\
\hline & Activation & & \\
\hline & Precuneous & 2.73 & $6,-64,26$ \\
\hline & Right Putamen & 3.01 & $\begin{array}{l}26,-2,-6 \\
\text { (Table Continues) }\end{array}$ \\
\hline
\end{tabular}


Table 3. (Continued)

\begin{tabular}{|c|c|c|c|}
\hline & Region & Z score & $(x, y, z)$ \\
\hline \multicolumn{4}{|c|}{ Sham-mindfulness meditation $>$ mindfulness meditation } \\
\hline \multirow[t]{7}{*}{ Activation } & Right cerebellum & 3.28 & $6,-66,-20$ \\
\hline & Left cerebellum & 3.01 & $-6,-54,-18$ \\
\hline & PAG & 4.68 & $0,-26,-6$ \\
\hline & Right thalamus & 2.73 & $8,-22,2$ \\
\hline & Left thalamus & 4.44 & $-8,-22,2$ \\
\hline & Left DLPFC & 2.67 & $-36,30,36$ \\
\hline & Right DLPFC & 4.67 & $28,42,36$ \\
\hline \multicolumn{4}{|c|}{ Conjunction: Mindfulness meditation + sham-mindfulness meditation } \\
\hline \multirow[t]{3}{*}{ Activation } & Right putamen & 2.82 & $24,4,-6$ \\
\hline & Left putamen & 3.12 & $-24,4,-6$ \\
\hline & Right SI & 3.04 & $48,-10,36$ \\
\hline \multirow[t]{8}{*}{ Deactivation } & $\mathrm{mPFC}$ & 3.26 & $6,58,-16$ \\
\hline & Right superior frontal gyrus & 2.79 & $6,52,32$ \\
\hline & Left superior frontal gyrus & 2.44 & $-6,56,32$ \\
\hline & $\mathrm{PCC} /$ precuneous & 8.00 & $6,-50,30$ \\
\hline & Right cerebellum & 7.19 & $6,-64,-28$ \\
\hline & Left cerebellum & 4.91 & $-6,-64,-28$ \\
\hline & Left DLPFC & 3.71 & $-24,32,36$ \\
\hline & Right DLPFC & 2.54 & $24,32,36$ \\
\hline \multicolumn{4}{|c|}{$\begin{array}{l}\text { Figure 7: MRI B: Neural correlates of group-manipulation } \\
\text { induced pain changes during "heat" series }\end{array}$} \\
\hline \multicolumn{4}{|c|}{ A: Neural correlates of mindfulness-based pain relief } \\
\hline \multicolumn{4}{|c|}{ Mean effect of mindfulness meditation } \\
\hline \multirow[t]{5}{*}{ Activation } & Right putamen & 3.29 & $24,2,2$ \\
\hline & Left putamen & 3.54 & $-24,2,2$ \\
\hline & Left inferior frontal gyrus & 4.03 & $-48,36,2$ \\
\hline & Right inferior frontal gryus & 2.96 & $48,36,2$ \\
\hline & Right SI & 3.07 & $46,-16,38$ \\
\hline \multirow[t]{2}{*}{ Deactivation } & mPFC & 4.37 & $0,60,16$ \\
\hline & $\mathrm{PCC}$ & 4.56 & $-4,-42,38$ \\
\hline \multicolumn{4}{|c|}{ Neural correlates of mindfulness-based pain intensity reductions } \\
\hline \multirow[t]{6}{*}{ Activation } & SgACC & 5.61 & $-6,40,-12$ \\
\hline & Right OFC & 7.65 & $28,44,-12$ \\
\hline & Left OFC & 4.45 & $-32,42,-12$ \\
\hline & Right anterior insula & 4.05 & $30,18,10$ \\
\hline & Right putamen & 9.12 & $26,8,10$ \\
\hline & Right inferior frontal gyrus & 2.95 & $40,20,10$ \\
\hline \multicolumn{4}{|c|}{ Neural correlates of mindfulness-based pain unpleasantness reductions } \\
\hline \multirow[t]{2}{*}{ Activation } & Left inferior frontal gyrus & 2.77 & $-48,20,4$ \\
\hline & Left frontal operculum & 2.68 & $-52,0,14$ \\
\hline \multicolumn{4}{|c|}{ Neural correlates of mindfulness-based pain intensity increases } \\
\hline Activation & Left inferior parietal lobe & 5.66 & $-42,-50,38$ \\
\hline \multicolumn{4}{|c|}{ B: Neural correlates of placebo-induced analgesia } \\
\hline Mean effect of pla & & & \\
\hline Activation & $\mathrm{ACC}$ & 3.87 & $10,44,22$ \\
\hline & Right DLPFC & 2.50 & $16,44,38$ \\
\hline & Left DLPFC & 3.96 & $-40,22,38$ \\
\hline Deactivation & Right posterior insula & 2.92 & $38,-16,8$ \\
\hline & Left posterior insula & 6.34 & $-38,-20,8$ \\
\hline & Left frontal operculum & 3.32 & $-34,14,8$ \\
\hline & Left SII/parietal operculum & 2.67 & $-40,-14,14$ \\
\hline & Right SII/parietal operculum & 2.73 & $36,-18,14$ \\
\hline & Left inferior frontal gyrus & 2.86 & $-52,14,14$ \\
\hline Neural correlates & & & \\
\hline Deactivation & Left SII/parietal operculum & 3.19 & $-50,-16,10$ \\
\hline & Left SII/parietal operculum & 3.91 & $-64,-16,10$ \\
\hline C: The mean effect of & & & \\
\hline Activation & SMA & 3.77 & $8,2,54$ \\
\hline & Left putamen & 4.15 & $-18,6,-4$ \\
\hline & Left thalamus & 3.60 & $-2,-14,-4$ \\
\hline & Right SI & 4.43 & $52,-12,42$ \\
\hline Deactivation & $\mathrm{ACC}$ & 2.93 & $8,48,12$ \\
\hline
\end{tabular}

$\overline{\mathrm{ACC}}$, Anterior cingulate cortex; SII, secondary somatosensory cortex; SI, primary somatosensory cortex; PCC, posterior cingulate cortex; mPFC, medial prefrontal cortex; DLPFC, dorsolateral prefrontal cortex; PAG, periaqueductal gray matter; sgACC, subgenual ACC; SMA, supplemental motor area; OFC, orbitofrontal cortex. 


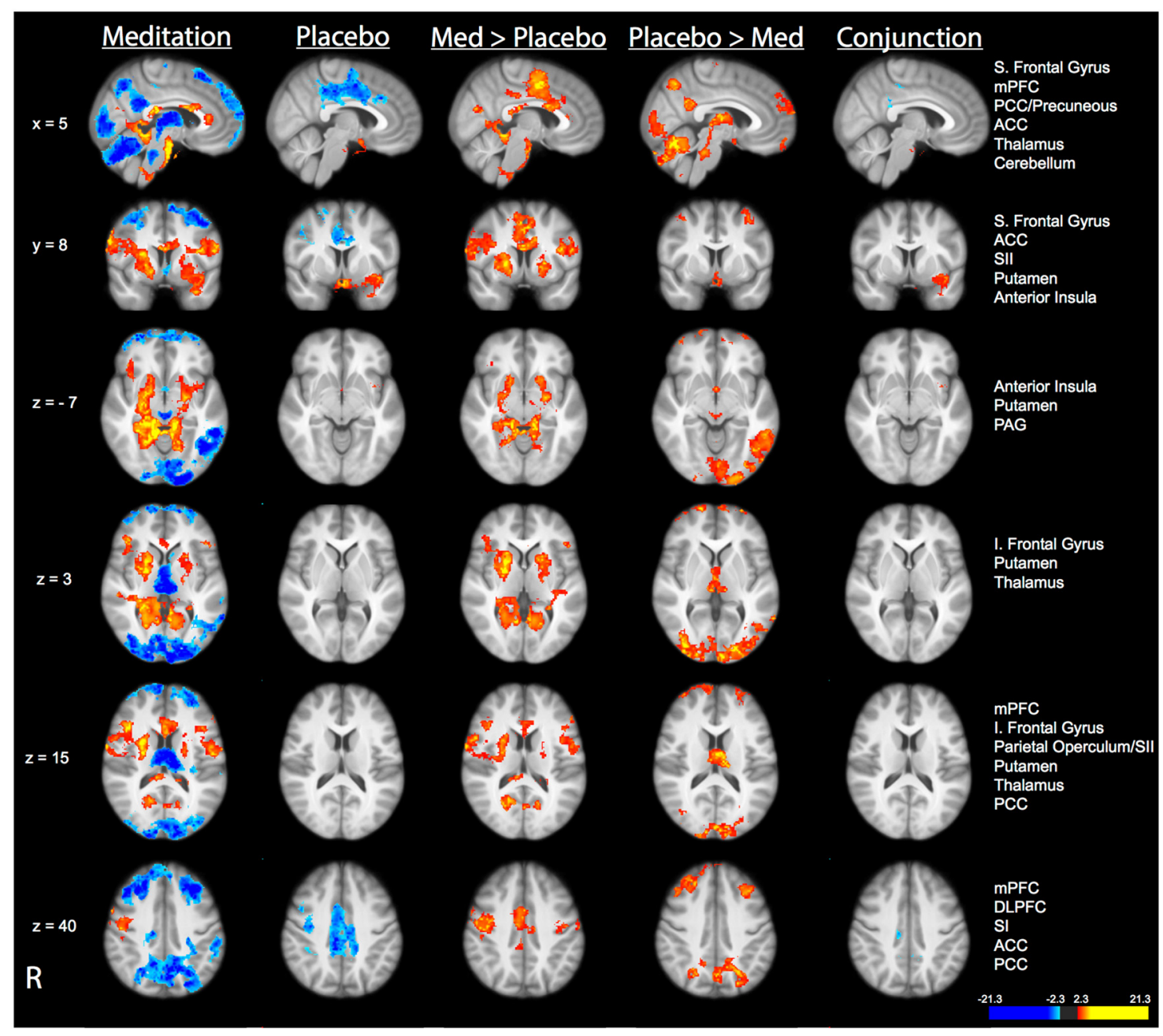

Figure 5. Brain activations and deactivations associated with the main effect of mindfulness meditation and placebo. Compared with pre-manipulation, mindfulness meditation produced significant activation in the bilateral anterior insula cortices, putamen, inferior (I) frontal gyrus, SII, and SI corresponding to the nose and face. Mindfulness meditation was also associated with significant deactivation in the thalamus, PAG, mPFC, DLPFC, cerebellum and PCC/precuneous. Placebo was associated with deactivation in brain regions ranging from the midcingulate cortex to the ACC. Placebo produced significant activation in the left anterior insula compared with pre-manipulation. Compared with placebo, mindfulness meditation produced significantly greater activation in the ACC, bilateral anterior insula, right putamen, and SI of the nose and face. Compared with mindfulness meditation, placebo produced greater activation in the DLPFC, mPFC, thalamus, PAG, PCC/precuneous, and cerebellum. Conjunction analyses revealed significant overlapping activation between the main effect of mindfulness meditation and placebo at the border between the ventral insula and medial temporal lobe. Slice locations correspond to standard stereotaxic space.

with greater activation in the contralateral inferior frontal gyrus and frontal operculum (Fig. 7A). During noxious heat stimulation, placebo produced greater activation in brain regions implicated in facilitating placebo analgesia, including the ACC and DLPFC (Fig. 7B; Petrovic et al., 2002; Wager et al., 2004; Benedetti et al., 2005; Bingel et al., 2006). Moreover, the placebo conditioning manipulation significantly attenuated pain-related activation in the bilateral posterior insula, SII, and contralateral frontal operculum compared with rest (pre-manipulation; Fig. $7 B$ ). Consistent with previous findings (Wager et al., 2004; Benedetti et al., 2005; Bingel et al., 2006; Wager et al., 2011), placebo produced greater activation in the ACC and DLPFC compared with the pre-manipulation condition. Regression analyses revealed individuals with greater placebo-induced pain intensity reductions were associated with greater reductions in the activation of the contralateral (to the stimulation site) regions of the SII/parietal operculum (Fig. 7B).
Mindfulness meditation and sham mindfulness meditation reduce pain through different mechanisms

The main effect of sham mindfulness meditation closely resembled that of the main effect of mindfulness meditation (Fig. 6). Conjunction analyses confirmed that sham mindfulness meditation produced significant overlapping activation with mindfulness meditation, including the bilateral anterior insula cortices, putamen, globus pallidus, ACC, SI representation of the nose (Gastl et al., 2014), and deactivation of brain regions associated with the default mode network of the brain (Raichle et al., 2001), including the PCC and mPFC (Fig. 6). Despite these overlapping patterns of activity, greater activation in the thalamus, PAG, bilateral DLPFC, and cerebellum was detected during sham mindfulness meditation compared with mindfulness meditation. In contrast, greater activation in the PCC and right globus pallidus was detected during mindfulness meditation when compared to sham mindfulness meditation. As with the placebo comparison, 


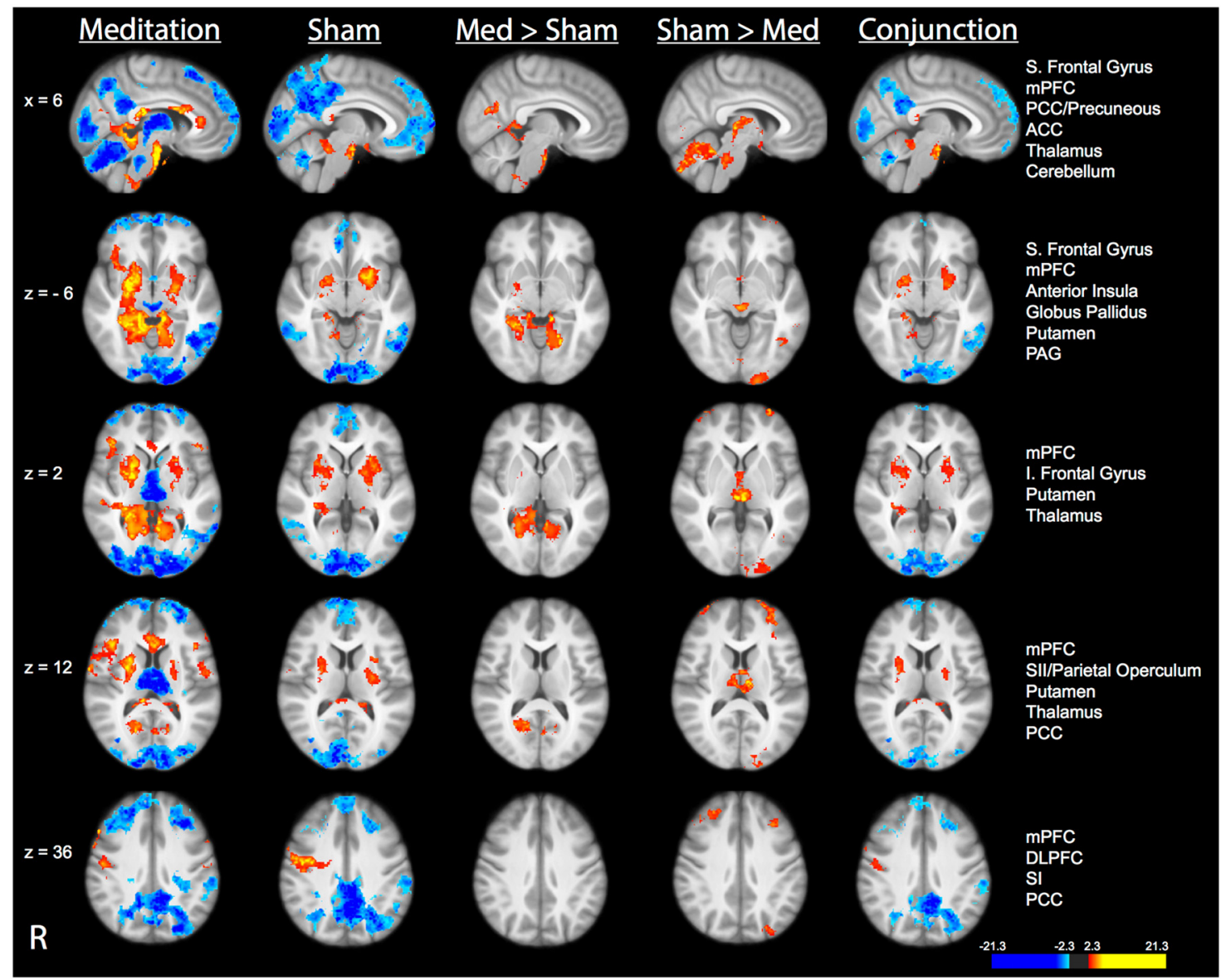

Figure 6. Brain activations and deactivations associated with the main effect of mindfulness meditation and sham mindfulness meditation. Sham mindfulness meditation produced significant activation in the globus pallidus, putamen and right $\mathrm{SI}$ of the nose and significant deactivation of the subgenual ACC, PCC, cerebellum and mPFC compared with pre-manipulation. Compared with sham mindfulness meditation, mindfulness meditation produced greater activation in the right putamen/globus pallidus and the PCC. Compared with mindfulness meditation, sham mindfulness meditation was associated with greater activation in the DLPFC, thalamus, PAG, and cerebellum. Conjunction analyses revealed significant overlapping activation in the bilateral putamen and SI corresponding to the nose and deactivation in the $\mathrm{MPFC}, \mathrm{PCC} /$ precuneous, and cerebellum. Slice locations correspond to standard stereotaxic space.

some of the differences between mindfulness and sham mindfulness meditation were associated with greater deactivation in one condition compared with the other (Fig. 6).

Across all individuals, sham mindfulness meditation produced greater activation in the thalamus, left putamen, SMA, PCC, and SI compared with pre-manipulation in the presence of noxious heat stimulation. There was also greater deactivation of the ACC, mPFC, and middle frontal gyrus (Fig. 7C). Importantly, regression analyses detected no significant relationship between interindividual changes in pain intensity/unpleasantness ratings and sham mindfulness meditation-related brain activation (Fig. 7C). However, sham mindfulness meditation-related pain relief was associated with reductions in respiration rate $\left(p=0.040, \mathrm{sr}^{2}=18 \%\right.$; see "Physiological data findings" for more details). In contrast, mindfulness-based pain relief was associated with greater activity in higher-order brain regions (i.e., OFC, sgACC, insula; Fig. $7 A$ ) and exhibited no significant ( $p=$ 0.426 ) relationship with changes in respiration rate (see "Physiological data findings" for more details).

\section{Physiological data findings}

Mindfulness and sham mindfulness meditation significantly reduced respiration rate

The ANOVA conducted on respiration rate detected a significant main effect of group $\left(F_{(3,71)}=3.43, p=0.021, \eta_{\mathrm{p}}^{2}=0.13\right.$ premanipulation vs post-manipulation, $F_{(1,71)}=82.12, p<0.001, \eta_{\mathrm{p}}^{2}=$
$0.54)$, but no main effect of "heat" versus "neutral" stimulation $\left(F_{(1,71)}=0.02, p=0.881\right)$. However, there was a significant premanipulation vs post-manipulation $\times$ group interaction $\left(F_{(3,71)}=\right.$ $\left.28.39, p<0.001, \eta_{\mathrm{p}}^{2}=0.55\right)$. These effects were associated with the significant percent reduction in respiration rate during mindfulness meditation and sham mindfulness meditation when compared to the pre-manipulation condition and comparison groups $(p<0.001$; Table 1). There were no significant differences in respiration rate from pre-manipulation to post-manipulation between the mindfulness meditation and sham meditation group $(p=0.316)$.

\section{Respiration rate and pain ratings}

To determine whether respiration rate differentially predicted changes in pain between groups, a multiple regression analysis tested the relationship between respiration rate and group on post-manipulation pain intensity and pain unpleasantness ratings, respectively. We first entered pre-manipulation pain intensity or pain unpleasantness ratings into the regression model. Next, pre-manipulation and post-manipulation respiration rate values were entered, respectively. Group was then entered to determine whether group uniquely contributed to the model. There was no significant relationship between group, respiration rate, and pain intensity ratings $(p=0.302)$. However, group uniquely contributed $\left(p=0.039, \mathrm{sr}^{2}=0.02\right.$; Table 4$)$ to the overall model on respiration rate and pain unpleasantness ratings. 


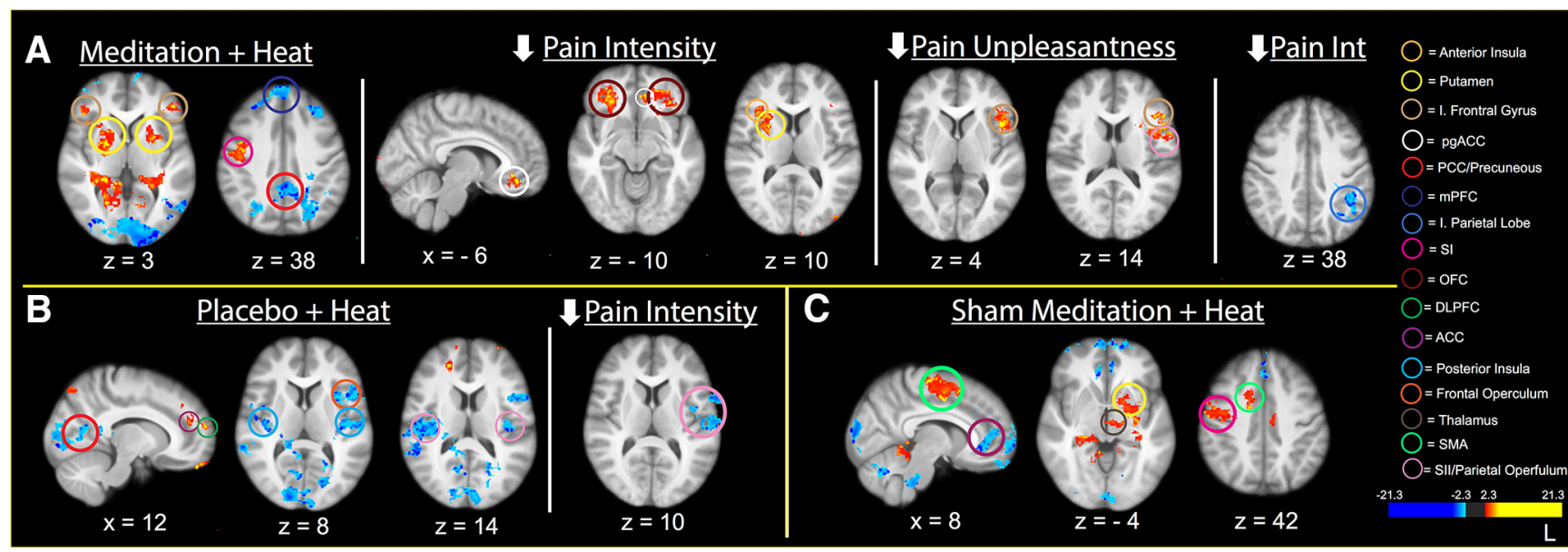

Figure 7. The relationship between group-manipulation-induced changes in pain ratings and brain activation during noxious stimulation. $A$, Top, Mindfulness meditation (meditation + heat) produced greater activation in the bilateral anterior insula, bilateral inferior (I) frontal gyrus, and the nose representation of the right SI and primary motor cortex (MI). Mindfulness meditation produced deactivation of the $\mathrm{MPFC}$ and PCC compared with pre-manipulation. Mindfulness-meditation-related decreases in pain intensity ratings were associated with greater activation in the bilateral $\mathrm{OFC}$, subgenual ACC, right anterior insula, and putamen. Greater deactivation of the left inferior parietal lobe was associated with greater pain intensity reductions. Meditation-induced reductions in pain unpleasantness ratings were associated with greater activation in the left inferior frontal gyrus and frontal operculum. $\boldsymbol{B}$, Bottom left, Placebo (placebo + heat) reduced pain-related activation in the bilateral frontal operculum, SII, posterior insula, and right inferior frontal gyrus. Placebo activated the ACC and DLPFC. Placebo-induced pain intensity reductions were associated with greater deactivation in the contralateral SII/parietal operculum. C, Bottom right, Sham mindfulness meditation (sham meditation + heat) produced deactivation of the ACC. Compared with pre-manipulation, there was greater sham mindfulness-meditation-related activation in the thalamus, SMA, right SI, and putamen.

Table 4. Multiple regression analysis assessing the relationship among pain unpleasantness ratings, respiration rate, and group in MRI session $B(n=75)$

\begin{tabular}{lrlclll}
\hline Variable & $B$ & SE $B$ & $\beta$ & sr $^{2}$ & Model $R^{2}$ & $F$ \\
\hline & & & & & 0.64 & $30.41^{*}$ \\
Pre-pain unpleasantness & 0.71 & 0.08 & $0.63^{*}$ & 0.40 & & \\
Pre-pain respiration rate & -0.02 & 0.06 & -0.03 & 0.0009 & & \\
Post-pain respiration rate & 0.16 & 0.05 & $0.33^{* *}$ & 0.06 & & \\
Group & -0.37 & 0.18 & $-0.20^{* * *}$ & 0.02 & &
\end{tabular}

$\bar{B}$, unstandardized beta coefficient; SE $B$, standard error of unstandardized beta coefficient; $\beta$, standardized beta coefficient; $\mathrm{sr}^{2}$, semi-partial coefficient squared; pre-pain unpleasantness, pre-manipulation-related pain unpleasantness ratings; pre-pain respiration rate, pre-manipulation respiration rate; post-pain respiration rate, postmanipulation respiration rate. ${ }^{*} p<0.001 .{ }^{* *} p=0.001 .{ }^{* * *} p=0.04$.

Table 5. Multiple regression analysis depicting the relationship between lower respiration rate and lower pain unpleasantness ratings for the sham-mindfulness meditation group $(n=20)$ in MRI session B

\begin{tabular}{lrcllll}
\hline Variable & $B$ & SE $B$ & $\beta$ & sr $^{2}$ & Model $R^{2}$ & $F$ \\
\hline & & & & & 0.44 & $4.25^{*}$ \\
Pre-pain unpleasantness & 0.50 & \multicolumn{1}{l}{16} & $0.60^{* *}$ & 0.32 & & \\
Pre-pain respiration rate & -0.03 & 0.09 & -0.07 & 0.004 & & \\
Post-pain respiration rate & 0.14 & 0.06 & $0.45^{* * *}$ & 0.18 & &
\end{tabular}

$B$, unstandardized beta coefficient; SE $B$, standard error of unstandardized beta coefficient; $\beta$, standardized beta coefficient; $\mathrm{sr}^{2}$, semi-partial coefficient squared; pre-pain unpleasantness, pre-manipulation-related pain unpleasantness ratings; pre-pain respiration rate, pre-manipulation respiration rate; post-pain respiration rate, respiration rate during sham meditation. ${ }^{*} p=0.02 .{ }^{* *} p=0.007 .{ }^{* * *} p=0.04$

To identify the groups that exhibited a significant relationship between pain unpleasantness changes and respiration rate, we conducted separate multiple regression analyses on each group. Similar to above, pre-manipulation pain unpleasantness ratings, pre-manipulation respiration rate, and post-manipulation respiration rate were entered into the model.

Lower respiration rate predicts pain relief during sham mindfulness meditation, but not during mindfulness meditation, placebo, or control conditions

The multiple regression analysis (Table 5) conducted on the sham mindfulness meditation group found that pre-manipulation pain unpleasantness ratings significantly contributed to the overall model
$\left(F_{(1,18)}=6.55, p=0.020\right)$ and accounted for $27 \%$ of the variance shared with pain unpleasantness ratings, whereas the premanipulation respiration rate did not covary with postpain unpleasantness ratings $(p=0.815)$. Importantly, lower respiration rate induced by sham mindfulness meditation significantly predicted lower pain unpleasantness ratings $\left(R^{2}\right.$ change $\left.=18 \%, p=0.040\right)$. When controlling for pre-manipulation pain unpleasantness ratings and pre-manipulation respiration rate, mindfulness-meditationrelated respiration rate was not associated with reductions in pain unpleasantness ratings $(p=0.426)$. Similar multiple regression analyses did not detect a significant relationship between changes in pain unpleasantness ratings and respiration rate in the placebo $(p=$ $0.906)$ or control ( $p=0.418)$ group.

Mindfulness and sham meditation were associated with significant reductions in global $C B F$

There was no significant main effect between groups on global $\operatorname{CBF}\left(F_{(3,71)}=0.49, p=0.688\right)$. Noxious heat produced significantly lower global $\mathrm{CBF}$ values compared with innocuous "neutral" stimulation $\left(F_{(1,71)}=24.61, p<0.001, \eta_{\mathrm{p}}^{2}=0.26\right)$; however, this effect did not vary by group $\left(F_{(3,71)}=0.21, p=\right.$ $0.889)$. The significant main effect of pre-manipulation versus post-manipulation $\left(F_{(1,71)}=51.05, p<0.001, \eta_{\mathrm{p}}^{2}=\right.$ 0.42 ) was associated with higher global CBF values during the pre-manipulation condition when compared to the postmanipulation condition. The significant pre-manipulation versus post-manipulation $\times$ group interaction on global $\mathrm{CBF}$ values $\left(F_{(3,71)}=15.04, p<0.001, \eta_{\mathrm{p}}^{2}=0.39\right.$; Table 1$)$ was driven by the significant reductions in global CBF values during mindfulness meditation $(-21 \%)$ compared with the sham mindfulness meditation $(p=0.001 ;-7 \%)$, placebo $(-2 \%$; $p<0.001)$, and control $(-4 \%$; $p<0.001)$ groups.

There were no significant changes in heart rate

Seven participant's heart rate data are not reported due to equipment malfunction. There were no significant between group differences in heart rate $\left(F_{(1,66)}=0.93, p=0.434\right.$; Table $1)$. There was also no significant main effect from pre- 
manipulation (rest) versus post-manipulation $\left(F_{(1,66)}=3.21\right.$, $p=0.078)$, pre-manipulation versus post-manipulation $\times$ group interaction $\left(F_{(3,66)}=0.45, p=0.715\right)$, differences between "heat" and "neutral" series $\left(F_{(1,66)}=0.28, p=0.601\right)$, stimulation series $\times$ group interaction $\left(F_{(3,66)}=0.23, p=\right.$ $0.874)$, pre-manipulation versus post-manipulation $\times$ stimulation series interaction $\left(F_{(1,66)}=0.11, p=0.747\right)$, or threeway interaction $\left(F_{(3,66)}=0.96, p=0.415\right)$.

\section{Discussion}

In the present study, mindfulness meditation reduced pain by engaging brain mechanisms that were distinct from those of placebo-induced analgesia as well as sham mindfulness meditation. Relative to the comparison groups, mindfulness meditation significantly decreased neural activation in brain regions crucially involved in the facilitation and modulation of nociceptive information (e.g., thalamus, PAG). We have also now repeatedly (Zeidan et al., 2011) found that mindfulness-meditation-based pain relief is not significantly associated with reductions in respiration rate, providing supplemental confirmation that mindfulness meditation is mechanistically distinct from the so-called "relaxation response" (Beary and Benson, 1974). In conjunction with previous findings (Gard et al., 2012; Grant et al., 2011; Zeidan et al., 2011; Lutz et al., 2013), the present data demonstrate that mindfulness-meditation-related pain relief is associated with greater brain activation in sensory processing regions (insula, SII) and unique cognitive reappraisal processes. However, this study is the first to demonstrate that mindfulness meditation is mechanistically distinct and produces reductions in pain intensity and pain unpleasantness ratings above and beyond the analgesic effects seen with either placebo conditioning or sham mindfulness meditation.

\section{Mindfulness meditation uses distinct neural mechanisms from placebo conditioning}

Consistent with the findings from our previous study (Zeidan et al., 2011), mindfulness-based pain relief engaged brain mechanisms involved in mediating the cognitive modulation of pain, including the anterior insula, sgACC, and OFC. The positive relationship between mindfulness-meditation-related pain relief and increased activation of the right anterior insula likely was associated with finetuning sensory evaluations in a context-dependent manner (Oshiro et al., 2009), whereas enhanced activations in the sgACC presumably mediated executive-level shifts between endogenously (i.e., breath) and exogenously driven (i.e., pain) attention (Davis et al., 1997). Importantly, the relationship between meditation-related pain relief and OFC activation likely reflects employment of unique reappraisal processes involved in altering the contextual evaluation of nociceptive sensory events (O'Doherty et al., 2001; Rolls and Grabenhorst, 2008).

The $4 \mathrm{~d}$ placebo conditioning intervention was very effective at reducing pain in MRI Session B, as reflected by an $11 \%$ reduction in pain intensity and a $13 \%$ reduction in pain unpleasantness ratings from the pre-manipulation baseline. In contrast, the control group reported a $16 \%$ increase in pain intensity and an $18 \%$ increase in pain unpleasantness ratings from baseline (Fig. 3). Although this is the first study to use arterial spin labeling MRI to image the brain regions involved in placebo analgesia, the present findings are consistent with previous work using BOLD fMRI (Petrovic et al., 2002; Wager et al., 2004; Koyama et al., 2005; Eippert et al., 2009) in demonstrating placebo-induced activation of the ACC and DLPFC and deactivation in the bilateral posterior insula and SII, brain regions involved in nociceptive processing (Coghill et al., 1994). Placebo cream-induced analgesia was correlated with reductions in pain-related activity in the contralateral SII. Although the main effect of mindfulness meditation was associated with significant deactivation of regions of the default mode network (PCC, mPFC) and the ACC, the main effect of placebo did not reduce activation in these regions. These results provide further evidence that mindfulness meditation is an active, cognitively engaging practice, whereas placebo reflects a more passive cognitive state, particularly in the absence of noxious stimulation.

\section{Mindfulness and sham mindfulness meditation reduce pain through different mechanisms}

To better understand the neural mechanisms associated with mindfulness meditation, the active components associated with mindfulness-based analgesia must be distinguished from those associated with the belief that one is practicing mindfulness meditation (MacCoon et al., 2012), alterations in breathing rate, bodily posture, and other potentially nonspecific factors (Zeidan et al., 2012; Tang et al., 2015). Therefore, a sham mindfulness meditation regimen was used to better characterize the specific analgesic mechanisms associated with mindfulness-based meditation. Importantly, whereas only the mindfulness meditation group significantly increased in mindfulness scores (+16\%; Fig. $4)$, there were no significant differences $(p>0.88)$ in "perceived meditative effectiveness" between the mindfulness and sham mindfulness meditation groups across their respective interventions (Table 2). These data demonstrate that the sham mindfulness meditation intervention was effective at leading participants to believe that they were practicing mindfulness meditation, but only the genuine mindfulness meditation intervention resulted in increases in mindfulness levels.

In the present study, sham mindfulness meditation produced significant reductions in pain ratings and engaged a neural network that partially overlapped with that exhibited by mindfulness meditation. Nevertheless, differences between these two cognitive practices were apparent during painful stimulation. First, mindfulness-based meditation produced significantly greater reductions in pain intensity $(-27 \%)$ and pain unpleasantness $(-44 \%)$ ratings than did sham mindfulness meditation (pain intensity reduction $=8 \%$; pain unpleasantness reduction $=$ $27 \%)$. Second, in the presence of noxious heat stimulation, sham mindfulness meditation produced greater activation in the thalamus, left putamen, SMA, PCC, and SI and greater deactivation of the ACC and mPFC when compared to rest. However, these analyses detected no significant relationship between interindividual changes in pain intensity/unpleasantness ratings and sham mindfulness meditation-related brain activation (Fig. 7). Similar to other breathing-related cognitive manipulations (Chalaye et al., 2009; Grant and Rainville, 2009; Martin et al., 2012), sham mindfulness meditation-induced analgesia was positively correlated with lower respiration rates (Table 5), which is consistent with mechanisms involved facilitating relaxation responses (Beary and Benson, 1974). In contrast, mindfulness-meditationreduced pain ratings were independent of respiration rate and achieved via neural mechanisms involved in the top-down regulation of pain (OFC; anterior insula; pgACC; Rainville, 2002).

\section{Considerations for mindfulness-based pain relief}

The purpose of this experiment was to determine whether mindfulness-meditation-induced analgesia engages distinct behavioral and neural mechanisms from those produced by placebo 
analgesia. However, given that the present study examined healthy, pain-free volunteers, we cannot explicitly generalize our findings to chronic pain patients. Nevertheless, significant time commitments have been described as a barrier to the clinical utilization of meditation (Wearn and Greenfield, 1998). We have repeatedly shown that as little as three $20 \mathrm{~min}$ daily sessions of mindfulness-based mental training can significantly reduce pain ratings and improve health measures (Zeidan et al., 2010b,c; Zeidan et al., 2014). The current data build upon these findings to reveal that mindfulness meditation produces significantly greater pain relief than do placebo-induced interventions and presumably results in enhanced pain relief because of the different neural mechanisms that are engaged. Consistent with the engagement of different neural mechanisms between mindfulness meditation and placebo, mindfulness meditation also produces differential effects on psychophysical ratings of pain. That is, mindfulness meditation produces greater reductions in pain unpleasantness relative to pain intensity (percent difference between pain intensity and unpleasantness $=-27 \%$ ) than placebo (percent difference between pain intensity and unpleasantness $=+3 \%$ ). It is also important to note that pain relief produced from the cognitive state of meditation does not likely produce lasting changes in the subjective experience of pain.

This study could not be designed in a double-blind fashion due to the nature of meditation training and placebo conditioning. Specifically, placebo cream could not be applied to all groups because this manipulation could potentially elicit analgesia even though the subjects were informed that the cream was inert (Kaptchuk et al., 2010). Furthermore, whereas subjects in the placebo-induced analgesia and book-listening control groups were clearly aware of their group assignment, subjects in the mindfulness and sham-mindfulness groups were blinded to their intervention assignment. For the mindfulness and shammindfulness groups, responses related to psychosocial influences (i.e., demand characteristics) presumably were minimal given that no significant differences in "perceived meditative effectiveness" were observed ( $p=0.88$; Table 2 ).

The present findings demonstrate that mindfulness meditation is superior in producing pain relief compared with other cognitive training regimens in which non-judgmental reappraisal is not an integral part of the mental training (the sham mindfulness meditation $\sim$ relaxation response). We postulate that a broader appreciation of these differences is an integral step in fostering the validity of mindfulness meditation as an adjunct therapy for mitigating pain and resultant suffering.

\section{References}

Abbott DF, Opdam HI, Briellmann RS, Jackson GD (2005) Brief breath holding may confound functional magnetic resonance imaging studies. Hum Brain Mapp 24:284-290. CrossRef Medline

Andersson J, Jenkinson M, Smith SM (2007a) Non-linear optimisation. FMRIB Technical Report TR07JA1. Available at http://www.fmrib.ox.ac. uk/analysis/techrep/\#TR07JA2.

Andersson J, Jenkinson M, Smith SM (2007b) Non-linear registration, aka spatial normalisation. FMRIB Technical Report TR07JA2. Available at http://www.fmrib.ox.ac.uk/analysis/techrep/\#TR07JA2.

Atlas LY, Whittington RA, Lindquist MA, Wielgosz J, Sonty N, Wager TD (2012) Dissociable influences of opiates and expectations on pain. J Neurosci 32:8053-8064. CrossRef Medline

Beary JF, Benson H (1974) A simple psychophysiologic technique which elicits the hypometabolic changes of the relaxation response. Psychosom Med 36:115-120. CrossRef Medline

Behzadi Y, Restom K, Liau J, Liu TT (2007) A component based noise cor- rection method (CompCor) for BOLD and perfusion based fMRI. Neuroimage 37:90-101. CrossRef Medline

Benedetti F, Mayberg HS, Wager TD, Stohler CS, Zubieta JK (2005) Neurobiological mechanisms of the placebo effect. J Neurosci 25:10390-10402. CrossRef Medline

Bingel U, Lorenz J, Schoell E, Weiller C, Büchel C (2006) Mechanisms of placebo analgesia: $\mathrm{rACC}$ recruitment of a subcortical antinociceptive network. Pain 120:8-15. CrossRef Medline

Birn RM, Murphy K, Handwerker DA, Bandettini PA (2009) fMRI in the presence of task-correlated breathing variations. Neuroimage 47:10921104. CrossRef Medline

Brown CA, Jones AK (2010) Meditation experience predicts less negative appraisal of pain: electrophysiological evidence for the involvement of anticipatory neural responses. Pain 150:428-438. CrossRef Medline

Buxton RB, Wong EC, Frank LR (1998) Dynamics of blood flow and oxygenation changes during brain activation: the balloon model. Magn Reson Med 39:855-864. CrossRef Medline

Chalaye P, Goffaux P, Lafrenaye S, Marchand S (2009) Respiratory effects on experimental heat pain and cardiac activity. Pain Med 10:1334-1340. CrossRef Medline

Coghill RC, Eisenach J (2003) Individual differences in pain sensitivity: implications for treatment decisions. Anesthesiology 98:1312-1314. CrossRef Medline

Coghill RC, Talbot JD, Evans AC, Meyer E, Gjedde A, Bushnell MC, Duncan GH (1994) Distributed processing of pain and vibration by the human brain. J Neurosci 14:4095-4108. Medline

Coghill RC, Sang CN, Berman KF, Bennett GJ, Iadarola MJ (1998) Global cerebral blood flow decreases during pain. J Cereb Blood Flow Metab 18:141-147. Medline

Coghill RC, Sang CN, Maisog JM, Iadarola MJ (1999) Pain intensity processing within the human brain: a bilateral, distributed mechanism. J Neurophysiol 82:1934-1943. Medline

Coghill RC, McHaffie JG, Yen YF (2003) Neural correlates of interindividual differences in the subjective experience of pain. Proc Natl Acad Sci U S A 100:8538-8542. CrossRef Medline

Cohen BH, Lea RB (2004) Essentials of statistics for the social and behavioral sciences. Hoboken, NJ: Wiley.

Colloca L, Petrovic P, Wager TD, Ingvar M, Benedetti F (2010) How the number of learning trials affects placebo and nocebo responses. Pain 151: 430-439. CrossRef Medline

Cropley M, Ussher M, Charitou E (2007) Acute effects of a guided relaxation routine (body scan) on tobacco withdrawal symptoms and cravings in abstinent smokers. Addiction 102:989-993. CrossRef Medline

Davis KD, Taylor SJ, Crawley AP, Wood ML, Mikulis DJ (1997) Functional MRI of pain- and attention-related activations in the human cingulate cortex. J Neurophysiol 77:3370-3380. Medline

Eippert F, Bingel U, Schoell ED, Yacubian J, Klinger R, Lorenz J, Büchel C (2009) Activation of the opioidergic descending pain control system underlies placebo analgesia. Neuron 63:533-543. CrossRef Medline

Fox MD, Snyder AZ, Vincent JL, Corbetta M, Van Essen DC, Raichle ME (2005) The human brain is intrinsically organized into dynamic, anticorrelated functional networks. Proc Natl Acad Sci U S A 102:9673-9678. CrossRef Medline

Gard T, Hölzel BK, Sack AT, Hempel H, Lazar SW, Vaitl D, Ott U (2012) Pain attenuation through mindfulness is associated with decreased cognitive control and increased sensory processing in the brain. Cereb Cortex 22:2692-2702. CrossRef Medline

Garland EL, Gaylord SA, Palsson O, Faurot K, Douglas Mann J, Whitehead WE (2012) Therapeutic mechanisms of a mindfulness-based treatment for IBS: effects on visceral sensitivity, catastrophizing, and affective processing of pain sensations. J Behav Med 35:591-602. Medline

Gastl M, Brünner YF, Wiesmann M, Freiherr J (2014) Depicting the inner and outer nose: The representation of the nose and the nasal mucosa on the human primary somatosensory cortex (SI). Hum Brain Mapp 35: 4751-4766. CrossRef Medline

Geuter S, Eippert F, Hindi Attar C, Büchel C (2013) Cortical and subcortical responses to high and low effective placebo treatments. Neuroimage 67: 227-236. CrossRef Medline

Grant JA, Rainville P (2009) Pain sensitivity and analgesic effects of mindful states in Zen meditators: a cross-sectional study. Psychosomatic Medicine 71:106-114. CrossRef Medline

Grant JA, Courtemanche J, Duerden EG, Duncan GH, Rainville P (2010) 
Cortical thickness and pain sensitivity in zen meditators. Emotion 10: 43-53. CrossRef Medline

Grant JA, Courtemanche J, Rainville P (2011) A non-elaborative mental stance and decoupling of executive and pain-related cortices predicts low pain sensitivity in Zen meditators. Pain 152:150-156. CrossRef Medline

Hölzel BK, Lazar SW, Gard T, Schuman-Olivier Z, Vago DR, Ott U (2011) How does mindfulness meditation work? Proposing mechanisms of action from a conceptual and neural perspective. Perspect Psychol Sci 6:537-559. CrossRef Medline

Jenkinson M, Bannister P, Brady M, Smith S (2002) Improved optimization for the robust and accurate linear registration and motion correction of brain images. Neuroimage 17:825-841. CrossRef Medline

Kabat-Zinn J (1982) An outpatient program in behavioral medicine for chronic pain patients based on the practice of mindfulness meditation: theoretical considerations and preliminary results. Gen Hosp Psychiatry 4:33-47. Medline

Kabat-Zinn J, Lipworth L, Burney R (1985) The clinical use of mindfulness meditation for the self-regulation of chronic pain. J Behav Med 8:163190. CrossRef Medline

Kaptchuk TJ, Friedlander E, Kelley JM, Sanchez MN, Kokkotou E, Singer JP, Kowalczykowski M, Miller FG, Kirsch I, Lembo AJ (2010) Placebos without deception: a randomized controlled trial in irritable bowel syndrome. PLoS One 5:e15591. CrossRef Medline

Kastrup A, Li TQ, Glover GH, Moseley ME (1999a) Cerebral blood flowrelated signal changes during breath-holding. AJNR Am J Neuroradiol 20:1233-1238. Medline

Kastrup A, Krüger G, Glover GH, Neumann-Haefelin T, Moseley ME (1999b) Regional variability of cerebral blood oxygenation response to hypercapnia. Neuroimage 10:675-681. CrossRef Medline

Kety SS, Schmidt CF (1948) The effects of altered arterial tensions of carbon dioxide and oxygen on cerebral blood flow and cerebral oxygen consumption of normal young men. J Clin Invest 27:484-492. CrossRef Medline

Kirk R (1995) Experimental design: procedures for the behavioral sciences, Ed 3. Pacific Grove, CA: Brooks/Cole.

Koyama T, McHaffie JG, Laurienti PJ, Coghill RC (2005) The subjective experience of pain: where expectations become reality. Proc Natl Acad Sci U S A 102:12950-12955. CrossRef Medline

Leber AB (2010) Neural predictors of within-subject fluctuations in attentional control. J Neurosci 30:11458-11465. CrossRef Medline

Lobanov OV, Quevedo AS, Hadsel MS, Kraft RA, Coghill RC (2013) Frontoparietal mechanisms supporting attention to location and intensity of painful stimuli. Pain 154:1758-1768. CrossRef Medline

Lobanov OV, Zeidan F, McHaffie JG, Kraft RA, Coghill RC (2014) From cue to meaning: brain mechanisms supporting the construction of expectations of pain. Pain 155:129-136. CrossRef Medline

Luh WM, Wong EC, Bandettini PA, Ward BD, Hyde JS (2000) Comparison of simultaneously measured perfusion and BOLD signal increases during brain activation with T(1)-based tissue identification. Magn Reson Med 44:137-143. Medline

Lui F, Colloca L, Duzzi D, Anchisi D, Benedetti F, Porro CA (2010) Neural bases of conditioned placebo analgesia. Pain 151:816-824. CrossRef Medline

Lutz A, McFarlin DR, Perlman DM, Salomons TV, Davidson RJ (2013) Altered anterior insula activation during anticipation and experience of painful stimuli in expert meditators. Neuroimage 64:538-546. CrossRef Medline

MacCoon DG, Imel ZE, Rosenkranz MA, Sheftel JG, Weng HY, Sullivan JC, Bonus KA, Stoney CM, Salomons TV, Davidson RJ, Lutz A (2012) The validation of an active control intervention for Mindfulness Based Stress Reduction (MBSR). Behav Res Ther 50:3-12. CrossRef Medline

Martin SL, Kerr KL, Bartley EJ, Kuhn BL, Palit S, Terry EL, DelVentura JL, Rhudy JL (2012) Respiration-induced hypoalgesia: exploration of potential mechanisms. J Pain 13:755-763. CrossRef Medline

Nichols T, Brett M, Andersson J, Wager T, Poline JB (2005) Valid conjunction inference with the minimum statistic. Neuroimage 25:653-660. CrossRef Medline

O'Doherty J, Kringelbach ML, Rolls ET, Hornak J, Andrews C (2001) Abstract reward and punishment representations in the human orbitofrontal cortex. Nat Neurosci 4:95-102. CrossRef Medline

Oshiro Y, Quevedo AS, McHaffie JG, Kraft RA, Coghill RC (2007) Brain mechanisms supporting spatial discrimination of pain. J Neurosci 27: 3388-3394. CrossRef Medline
Oshiro Y, Quevedo AS, McHaffie JG, Kraft RA, Coghill RC (2009) Brain mechanisms supporting discrimination of sensory features of pain: a new model. J Neurosci 29:14924-14931. CrossRef Medline

Penfield W, Boldrey E (1937) Somatic motor and sensory representation in the cerebral cortex of man as studied by electrical stimulation. Brain 60:389. CrossRef

Petrovic P, Kalso E, Petersson KM, Ingvar M (2002) Placebo and opioid analgesia- imaging a shared neuronal network. Science 295:1737-1740. CrossRef Medline

Petrovic P, Kalso E, Petersson KM, Andersson J, Fransson P, Ingvar M (2010) A prefrontal non-opioid mechanism in placebo analgesia. Pain 150: 59-65. CrossRef Medline

Price DD (2000) Psychological and neural mechanisms of the affective dimension of pain. Science 288:1769-1772. CrossRef Medline

Price DD, McGrath PA, Rafii A, Buckingham B (1983) The validation of visual analogue scales as ratio scale measures for chronic and experimental pain. Pain 17:45-56. CrossRef Medline

Price DD, Bush FM, Long S, Harkins SW (1994) A comparison of pain measurement characteristics of mechanical visual analogue and simple numerical rating scales. Pain 56:217-226. CrossRef Medline

Price DD, Milling LS, Kirsch I, Duff A, Montgomery GH, Nicholls SS (1999) An analysis of factors that contribute to the magnitude of placebo analgesia in an experimental paradigm. Pain 83:147-156. CrossRef Medline

Quevedo AS, Coghill RC (2007a) Attentional modulation of spatial integration of pain: evidence for dynamic spatial tuning. J Neurosci 27:1163511640. CrossRef Medline

Quevedo AS, Coghill RC (2007b) An illusion of proximal radiation of pain due to distally directed inhibition. J Pain 8:280-286. CrossRef Medline

Quevedo AS, Coghill RC (2009) Filling-in, spatial summation, and radiation of pain: evidence for a neural population code in the nociceptive system. J Neurophysiol 102:3544-3553. CrossRef Medline

Raichle ME, MacLeod AM, Snyder AZ, Powers WJ, Gusnard DA, Shulman GL (2001) A default mode of brain function. Proc Natl Acad Sci U S A 98:676-682. CrossRef Medline

Rainville P (2002) Brain mechanisms of pain affect and pain modulation. Curr Opin Neurobiol 12:195-204. CrossRef Medline

Restom K, Behzadi Y, Liu TT (2006) Physiological noise reduction for arterial spin labeling functional MRI. Neuroimage 31:1104-1115. CrossRef Medline

Rolls ET, Grabenhorst F (2008) The orbitofrontal cortex and beyond: from affect to decision-making. Prog Neurobiol 86:216-244. CrossRef Medline

Salomons TV, Kucyi A (2011) Does Meditation Reduce Pain through a Unique Neural Mechanism? J Neurosci 31:12705-12707. CrossRef Medline

Shin DD, Liu TT, Wong EC, Shankaranarayanan A, Jung Y (2012) Pseudocontinuous arterial spin labeling with optimized tagging efficiency. Magn Reson Med 68:1135-1144. CrossRef Medline

Smith SM, Jenkinson M, Woolrich MW, Beckmann CF, Behrens TE, Johansen-Berg H, Bannister PR, De Luca M, Drobnjak I, Flitney DE, Niazy RK, Saunders J, Vickers J, Zhang Y, De Stefano N, Brady JM, Matthews PM (2004) Advances in functional and structural MR image analysis and implementation as FSL. Neuroimage 23:S208-S219. CrossRef Medline

Starr CJ, Sawaki L, Wittenberg GF, Burdette JH, Oshiro Y, Quevedo AS, Coghill RC (2009) Roles of the insular cortex in the modulation of pain: insights from brain lesions. J Neurosci 29:2684-2694. CrossRef Medline

Tan H, Maldjian JA, Pollock JM, Burdette JH, Yang LY, Deibler AR, Kraft RA (2009) A fast, effective filtering method for improving clinical pulsed arterial spin labeling MRI. J Magn Reson Imaging 29:1134-1139. CrossRef Medline

Tancredi FB, Gauthier CJ, Madjar C, Bolar DS, Fisher JA, Wang DJ, Hoge RD (2012) Comparison of pulsed and pseudocontinuous arterial spinlabeling for measuring CO2 -induced cerebrovascular reactivity. J Magn Reson Imaging 36:312-321. CrossRef Medline

Tang YY, Hölzel BK, Posner MI (2015) The neuroscience of mindfulness meditation. Nat Rev Neurosci 16:213-225. CrossRef Medline

Toothaker LE (1993) Multiple comparison procedures. Newbury Park, CA: Sage.

Ussher M, Cropley M, Playle S, Mohidin R, West R (2009) Effect of isometric exercise and body scanning on cigarette cravings and withdrawal symptoms. Addiction 104:1251-1257. CrossRef Medline

Wager TD, Atlas LY (2015) The neuroscience of placebo effects: connecting 
context, learning and health. Nat Rev Neurosci 16:403-418. CrossRef Medline

Wager TD, Rilling JK, Smith EE, Sokolik A, Casey KL, Davidson RJ, Kosslyn SM, Rose RM, Cohen JD (2004) Placebo-induced changes in FMRI in the anticipation and experience of pain. Science 303:1162-1167. CrossRef Medline

Wager TD, Atlas LY, Leotti LA, Rilling JK (2011) Predicting individual differences in placebo analgesia: contributions of brain activity during anticipation and pain experience. J Neurosci 31:439-452. CrossRef Medline

Walach H, Buchheld N, Buttenmuller V, Kleinknecht N, Schmidt S (2006) Measuring mindfulness-the Freiburg Mindfulness Inventory (FMI). Personality and Individual Differences 40:1543-1555. CrossRef

Wearn AM, Greenfield SM (1998) Access to complementary medicine in general practice: survey in one UK health authority. J R Soc Med 91:465470. Medline

White G (1908) Natural history and antiquities of selborne. London: Cassell.

Woolrich MW, Ripley BD, Brady M, Smith SM (2001) Temporal autocorrelation in univariate linear modeling of FMRI data. Neuroimage 14: 1370-1386. CrossRef Medline

Worsley KJ (2001) Statistical analysis of activation images. In: Functional MRI: An Introduction to Methods (Jezzard P, Matthews PM, Smith SM, eds). New York: OUP.

Worsley KJ, Evans AC, Marrett S, Neelin P (1992) A three-dimensional statistical analysis for CBF activation studies in human brain. J Cereb Blood Flow Metab 12:900-918. CrossRef Medline
Yelle MD, Oshiro Y, Kraft RA, Coghill RC (2009) Temporal filtering of nociceptive information by dynamic activation of endogenous pain modulatory systems. J Neurosci 29:10264-10271. CrossRef Medline

Zeidan F, Gordon NS, Merchant J, Goolkasian P (2010a) The effects of brief mindfulness meditation training on experimentally induced pain. J Pain 11:199-209. CrossRef Medline

Zeidan F, Johnson SK, Gordon NS, Goolkasian P (2010b) Effects of brief and sham mindfulness meditation on mood and cardiovascular variables. J Altern Complement Med 16:867-873. CrossRef Medline

Zeidan F, Johnson SK, Diamond BJ, David Z, Goolkasian P (2010c) Mindfulness meditation improves cognition: evidence of brief mental training. Conscious Cogn 19:597-605. CrossRef Medline

Zeidan F, Martucci KT, Kraft RA, Gordon NS, McHaffie JG, Coghill RC (2011) Brain mechanisms supporting the modulation of pain by mindfulness meditation. J Neurosci 31:5540-5548. CrossRef Medline

Zeidan F, Grant JA, Brown CA, McHaffie JG, Coghill RC (2012) Mindfulness meditation-related pain relief: evidence for unique brain mechanisms in the regulation of pain. Neurosci Lett 520:165-173. CrossRef Medline

Zeidan F, Martucci KT, Kraft RA, McHaffie JG, Coghill RC (2014) Neural correlates of mindfulness meditation-related anxiety relief. Soc Cogn Affect Neurosci 9:751-759. Medline

Zeidan F, Lobanov OV, Kraft RA, Coghill RC (2015) Brain mechanisms supporting violated expectations of pain. Pain 156:1772-1785. CrossRef Medline 